\title{
A PROTEOMIC ANALYSIS OF DIFFERENTIATION IN THE MAMMARY EPITHELIUM
}

\author{
A Thesis \\ presented to \\ the Faculty of California Polytechnic State University, \\ San Luis Obispo
}

In Partial Fulfillment

of the Requirements for the Degree

Master of Science in Agriculture, with a Specialization in Animal Science

By

Laura Therese Strand

June 2012 
C)2012

Laura Therese Strand ALL RIGHTS RESERVED 


\section{COMMITTEE MEMBERSHIP}

TITLE:

AUTHOR:

DATE SUBMITTED:

June 2012
A Proteomic Analysis of Differentiation in the

Mammary Epithelium

Laura Therese Strand

COMMITTEE CHAIR:

Dr. Daniel G. Peterson, PhD

COMMITTEE MEMBER: Dr. Lars Tomanek, PhD

COMMITTEE MEMBER: $\quad$ Dr. Candace Winstead, PhD 


\begin{abstract}
A Proteomic Analysis of Differentiation in the Mammary Epithelium
\end{abstract}

\title{
Laura Therese Strand
}

While a great deal is known about the changing hormonal environment and the structural development of the mammary gland from pregnancy to lactation, very little is known about the molecular mechanisms governing differentiation of the mammary epithelium into a milk-secreting phenotype. It is important to acknowledge the diversity among the mammary glands of different species in order to better understand applications in human health and the dairy industry. In this study, we examined global protein expression during two states of differentiation in mammary epithelial cells from two species: in vitro proliferating and differentiated MAC-T cells (a bovine immortal cell-line), and primary mammary epithelial cells isolated from pregnant and lactating mice. When comparing the lists of proteins that differed in abundance in the two experiments, we observed many similarities in proteins related to structural dynamics and mRNA processing within these two mammary epithelial cell types. Intriguingly, we observed several differences in the regulation of metabolic proteins, highlighting the distinct pathways by which different species probably metabolize energy and synthesize milk components. 


\section{ACKNOWLEDGEMENTS}

I would like to acknowledge Dr. Daniel Peterson for his guidance, advice and unwavering patience throughout the journey that has culminated in this thesis. I would also like to thank Marcus Zuzow and James Koman for all of their help in the proteomics department and last, but certainly not least, all of the lab-mates with whom I have shared

the graduate school experience, Tasha Johnson, Molly Strong, Lisa McDonnell and Alyssa Conly. 


\section{TABLE OF CONTENTS}

Page

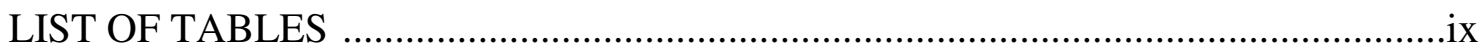

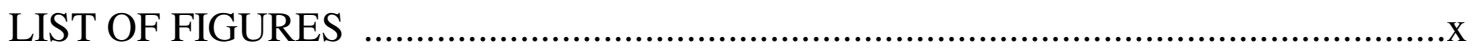

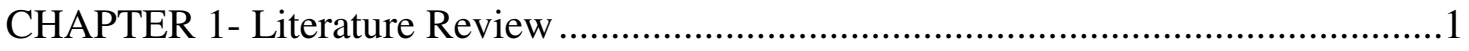

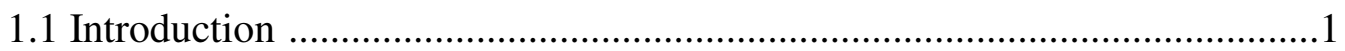

1.2 Mammary Structure/Architecture ......................................................2

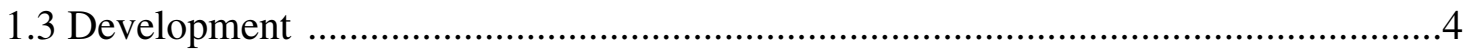

1.3.1 Overview .........................................................................

1.3.2 Embryonic Development ...............................................6

1.3.3 Pubertal Development.....................................................

1.3.4 Development During Pregnancy .............................................11

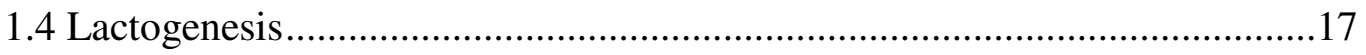

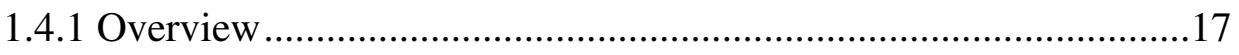

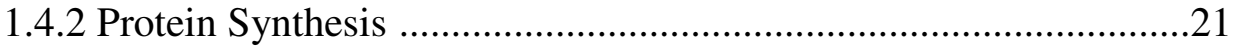

1.4.3 Lactose Synthesis..............................................................24

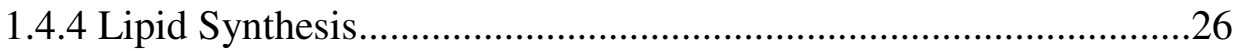

1.4.4.1 Pentose Phosphate Pathway .......................................31

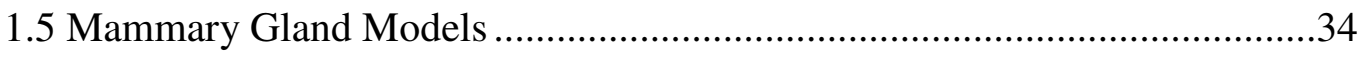

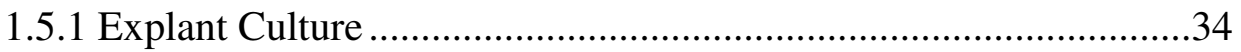

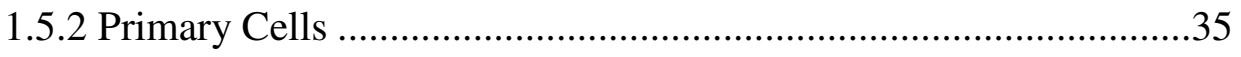

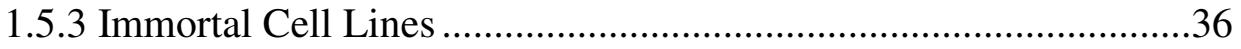




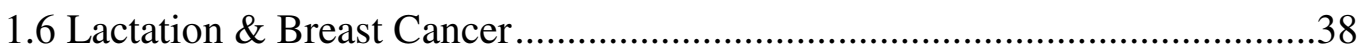

1.6.1 Breast Cancer Biomarkers ............................................................39

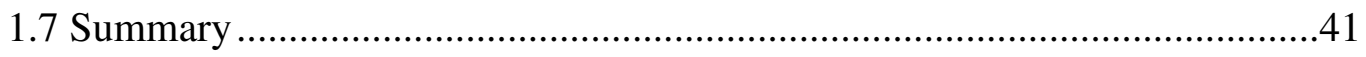

CHAPTER 2 - Proteomic Analysis of Differentiation in the MAC-T Cell Line.............42

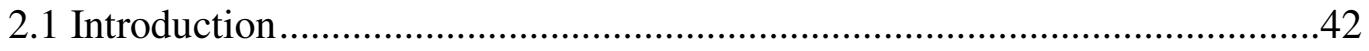

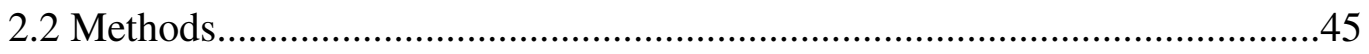

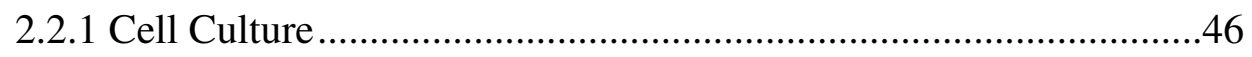

2.2.2 Protein Extraction ........................................................................

2.2.3 Two-Dimensional Gel Electrophoresis (2D) ..................................48

2.2.4 Tryptic Digestion and MALDI TOF/TOF Mass Spectrometry ......49

2.2.5 Protein Analysis .........................................................................51

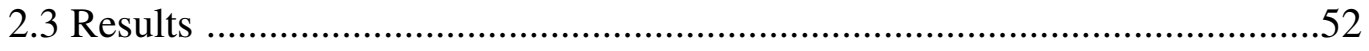

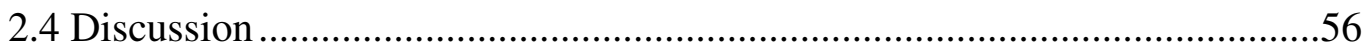

CHAPTER 3 - A proteomic analysis of differentiation, in vivo through the comparison of primary mammary epithelial cells from pregnant and lactating mice .....67

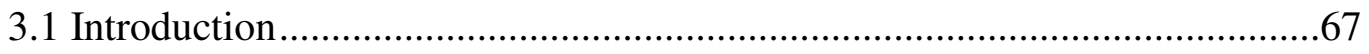

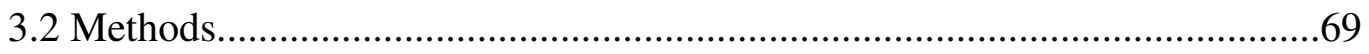

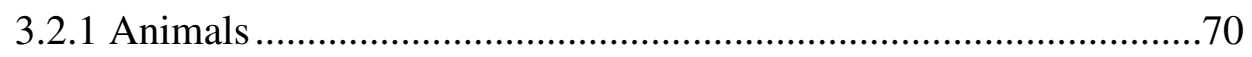

3.2.2 Primary Cell Isolation ..................................................................

3.2.3 Protein Isolation, 2DE, Tryptic Digestion and

MALDI TOF/TOF Mass Spectrometry and Data Analysis.......................72 
3.3 Results. .74

3.4 Discussion .82

CHAPTER 4 - Summary .89

List of References .92

Appendix - Flow Cytometry Data/Analysis 100 


\section{LIST OF TABLES}

Table

Page

1. Identified proteins that differed in abundance between proliferating and

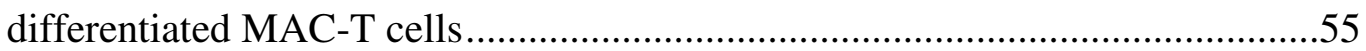

2. Identified proteins that differed in abundance between mammary epithelial cells isolated from pregnant and lactating mice............................................78 


\section{LIST OF FIGURES}

Figure

Page

1. Fatty Acid Synthesis .

2. NADPH Production

a. Non-Ruminant NADPH Production .30

b. Ruminant NADPH Production .30

3. Fused Gel Image of MAC-T Protein Spots. .53

4. Heat Map - Significant MAC-T Proteins .54

5. Fused Gel Image of Primary Murine Mammary Epithelial Cell Protein Spots ...76

6. Heat Map - Significant Primary Murine Mammary Epithelial Cell Proteins .....77 
CHAPTER 1- Literature Review

\subsection{Introduction}

The words Mammalia and "mammary" are both derived from the Latin word mamma meaning "breast", so it is no surprise that the ability of the mammary gland to provide nutrition for neonatal young is a defining factor setting this class of animal apart from other vertebrates (Miriam-Webster, 2012). While most mammary related research has been conducted in mouse models, it is important to acknowledge the diversity among the mammary glands of different species in order to better understand applications in human health and the dairy industry. Species-specific differences are not restricted to the structure and tissue architecture and include differences in hormonal and metabolic regulation of both development and lactation (Capuco, 2002). The purpose of this review is to address some of these similarities and divergences as they apply to mammary biology from development through lactation. 


\subsection{Mammary Structure/Architecture}

The mammary gland is one of few organs in which the majority of development occurs postnatally. It also has the unique ability to cycle from structural maturation through the production of milk and an apoptotic regression to quiescence. Theoretically, this cycle can repeat continuously from first estrus until menopause based on the number of offspring and length of time the young are nursed (Knight, 1982).

The mature, non-lactating mammary gland consists mostly of stroma, or a structural matrix of support provided by connective tissue, collagen and adipose tissue. Postnatally, the fat pad is responsible for not only structural support, but also to provide the mammary gland with contact to vasculature, the lymphatic system, lipids and local growth factor synthesis (Hovey, 1999). The matrix provides the ideal environment for the branching ductal system that makes up the region of the mammary gland responsible for the synthesis and secretion of milk. The ductal mammary epithelium is made up of several cell type subpopulations: a single layer of squamous, myoepithelial cells surround cuboidal, luminal epithelial cells (responsible for synthesis and secretion of milk components) and at the terminus of the ducts there are multiple layers of cells with the stem-like ability to proliferate further or differentiate into secretory cells upon establishment of pregnancy (Gjorevski, 2011). Throughout pregnancy the mammary gland develops structurally and epithelial ducts culminate in the formation of alveoli. Secretory alveoli are hollow sacs made up internally of a single-layer of cuboidal, secretory epithelium connected by tight junctions (Delamaire, 2006). The surrounding 
outer layers of squamous myoepithelium are not secretory cells, but do have contractile capabilities for the purpose of milk movement.

The fat pad surrounding these structures is not an inert element of the mammary gland. It has been suggested that the presence of adipose tissue is not only paramount to the formation of ductal structures, but also to the total milk yield potential of a gland; the number of epithelial cells a gland contains is directly correlated with both the amount of adipose tissue in the fat pad and the volume of milk a gland can produce (Hovey, 1999). While the stroma of the mammary tissue does not secrete milk components, adipose cells and connective tissue do contribute to lactation through structural support and paracrine secretion of lactation signals. For example, when estrogen receptor alpha (ER- $\alpha)$ is knocked down in the stroma, the epithelium remains under-developed due to the lack of hepatocyte growth factor (HGF), which is normally secreted by adipocytes in response to the binding of estrogen (E2) to ER- $\alpha$ (Gjorevski, 2011). Recent research indicates that this "cross-talk" between the mammary fat pad and the expanding epithelium is necessary for the development of the gland as neither stroma nor epithelium will function to its full potential without the adjacency of the other (Berry, 2003). 


\subsection{Development}

\subsubsection{Overview}

Although a rudimentary mammary gland exists from birth and expands structurally at puberty, the mammary gland has not reached its full potential until it has functionally developed milk-making machinery, which may allow a dam to independently support the life of her offspring. This chapter will describe the stages of growth within the mammary gland from fetal development, through pregnancy, as the gland prepares for the synthesis of milk. Lactation, specifically the process of milk synthesis, will be described in depth in the following chapter.

The term "mammogenesis" refers to the first stage of functional development during pregnancy when the mammary gland begins to prepare structurally for lactation. This growth is exponential until parturition and the onset of lactation (Knight, 1982). Lactogenesis, or final differentiation of the extensively developed epithelium occurs in two stages resulting in the functional milk producing machinery (Tucker, 1981). The first stage of change within the epithelium is the increase in milk-related enzyme activity, initiation of lipogenesis and the translation of milk proteins such as lactose, caseins, alpha-lactalbumin and beta-lactoglobulin. Morpholigically, lactogenesis can be distinguished by the formation of intracellular lipid droplets (Brisken, 2006). The second stage of lactogenesis involves alveologenesis as tight junctions close between alveolar epithelial cells and intracellular milk proteins and lipid droplets are secreted into the 
alveolar lumen due to the hormonal environment achieved through parturition and stimulation (Foster, 1977).

Once lactation has begun, galactopoesis is the term associated with the maintenance of lactation for a period long enough to nurture growing offspring and ends in involution, the process of apoptosis of secretory cell types through the gradual weaning process and the return to a quiescent state (Knight, 1982). Milk composition varies between species, between individuals and within individuals but is not significantly affected by frequency of milking or volume of milk produced (Delamaire, 2006). Galactopoesis can be manipulated and extended through manual milking, a factor upon which the dairy industry is based, however, the period of lactation is not indefinite and regardless of frequency or milk yield, lactation will peak, regress and eventually cease (Amos, 1985). Each of these developmental stages relies on the complex relationship between a variety of hormones produced by the ovaries, anterior and posterior pituitary and locally within the mammary gland (Perry, 2008). 


\subsubsection{Embryonic Development}

In the abdomen of a prenatal mammal, pairs of "placodes" (pre-organ regions of thickened epithelium) form within the subcutaneous epithelial layer (Gjorevski, 2011). Near the end of gestation, these placodes invaginate the adjacent mesenchyme so that at birth, the mammary gland consists of a subcutaneous fat pad containing a very rudimentary, branched ductal epitheilum (Mukhina, 2006). Fetal development of the epithelium relies heavily on the adjacent inductive mammary mesenchyme that develops in the mammalian embryo. However, this stage of development occurs even though the rudimentary gland is deficient in receptors for any hormones typically linked with postnatal development including estrogen, prolactin, growth hormone, progesterone or growth factor receptors such as insulin-like growth factor-1 (IGF-1) and epidermal growth factor (EGF) (Hens, 2005). This expansion without hormonal cues is poorly understood, but further research may shed light on hormone resistant (i.e. ER-) mammary gland cancer (Hens, 2005). The mammary mesenchyme does have the ability to respond to androgens and it has been implicated as a possible target for sex hormones in the process of sexual dimorphism and cessation of development in the male mammary gland (Hovey, 1999). Prior to sexual maturation there is a period of allometric growth providing a more complex matrix of structural support for a future functional mammary gland (Mukhina, 2006). 


\subsubsection{Pubertal Development}

The pubertal transition, termed ductal morphogenesis, allows the ductal system to permeate the stroma and fill the fat pad with a more elaborate branched epithelial system (Mukhina, 2006). The puberty-associated shift in circulating ovarian hormones, such as estrogen, cause extensive proliferation of the mammary gland epithelium to the limits of the fat pad and the formation of quiescent boundaries identified as terminal end buds (TEB) in mice. TEBs are multilayered structures surrounded by a basement membrane. While ducts contain single layers of contractile myoepithelial cells and luminal epithelial cells, the "cap" of the TEB contains multiple layers of cells with the stem-like ability to proliferate further or differentiate into secretory cells upon establishment of pregnancy (Gjorevski, 2011).

In humans, stem cells have been detected in the terminal ducts rather than the caps of lobules. Mammary stem cells can become a variety of cell types depending on hormonal cues and it has been demonstrated that one mammary stem cell has the ability to repopulate an entire gland (Gjorevski, 2011). The stem cell populations in the TEB end cap of mice express a marker of multipotent stem cells called s-SHIP and the presence of stem cells is imperative to the extension of ducts during puberty. Macrophages eosinophils and mast cells, three immune cells, are also critical members of the mammary gland stroma; without them, stem cells are unable to functionally re-populate the mammary gland. While macrophages facilitate the action of stem cells by promoting the formation of long collagen fibers around the base of the TEB, which are believed to 
support ductal elongation, mast cells induce branching of the mammary gland through the secretion of serine proteases. The epithelium has been shown to secrete macrophage colony-stimulating factor 1 (CSF1) and eotaxin, which may be responsible for the recruitment of macrophages and eosinophils to the TEB (Gjorevski, 2011).

It is well-established that ovarian hormones play a role in mammary morphogenesis, but there are species-related discrepancies over whether or not normal proliferating mammary epithelial cells express ER or progesterone receptor (PR; Capuco, 2002). There are two main subtypes of ER: ER- $\alpha$ and ER- $\beta$. In humans, cows, and rats, the ER is localized to a subpopulation of non-proliferative epithelial cells, but studies in mice have shown some evidence of ER+ proliferating cells and stromal cells (Capuco, 2002). Estrogen, specifically estradiol (E2), is believed to be the main driver of ductal elongation or longitudinal growth during puberty (Stingl, 2011). A review published by Brisken, et al. (2006) considered data from several studies to illustrate that ER- $\alpha$ deficient mice are completely infertile, but if ER- $\alpha$ is knocked out after sexual maturation, milk proteins were still transcribed during pregnancy. These results indicate that ER- $\alpha$ is necessary for mammary development during puberty yet may play a smaller role postpuberty and during lactation (Briskin, 2006). ER- $\beta$ deficient mice have been shown to develop ovarian defects and although they are able to lactate they express underdeveloped stroma and reduced milk secretion. Whether or not this is due specifically to lack of epithelial E2 signaling or a symptom of general endocrine disruption, which would be a likely complication of defective ovaries as E2 is not the only hormone they secrete, has not yet been determined (Briskin 2006). Regardless, it is believed that E2 is 
exhibiting its proliferative effects on the whole epithelium mostly through paracrine signaling through induction of amphiregulin secretion by ER- $\alpha+$ cells. Amphiregulin is a known cell-growth modulator and shares a significant homology with EGF allowing it to bind the EGF receptor (Shoyab, 1989).

Progesterone is the other key ovarian hormone associated with proliferation during pubertal development, but it requires the presence of estrogen for maximal effects (Stingl 2011). In fact, expression of PR is autoregulated by both E2 and progesterone ligand binding (Shyamala, 2002). Progesterone receptor abundance in the mammary epithelium increases with puberty, but is only detected in approximately $55 \%$ of epithelial cells and exclusively luminal epithelial cells, not in myoepithelial cells or surrounding stroma (Shyamala, 2002). There are two isoforms of PR: PRA and PRB. These receptors are derived from transcription of the same gene, differing due to two distinct promoters leading to overlapping, but distinct sequences. The longer form (PRB) contains an additional 164 amino acids termed the "B-upstream region" at the N-terminal end of the protein (Gadkar-Sable, 2005). PRB is the predominant receptor responsible for mediation the action of progesterone within the mammary gland during puberty, although PRA is up-regulated upon initiation of pregnancy. (Briskin, 2006; Stingl, 2011). Progesterone acts by inducing receptor activator for nuclear factor kb ligand (RANKL), which in turn binds its receptor (RANK) and induces the side-branching or lateral spread of the ductal system (Stingl, 2011). 
Development of the mammary gland does not rely on ovarian hormones alone, however, as evidenced by studies concluding exogenous E2 treatment to be insufficient to rescue branching of the mammary epithelium in animals that have had their pituitary gland removed. Proliferation of the epithelium requires both growth hormone $(\mathrm{GH})$, secreted by the anterior pituitary, and insulin-like growth factor I (IGF-1) expressed by many tissues in the body, one of which being the mammary gland (Capuco, 2002). Locally produced IGF-1 from stromal cells, and associated binding proteins, may actually mediate the exposure and response of the mammary epithelium to circulating GH and E2 (Akers, 2005). For example, in pubertal rodents, GH treatment has been shown to increase the abundance of estrogen receptors as well as stimulating IGF-1 secretion from stromal cells (Akers, 2005). The roles of E2, GH and IGF-1 do not end with puberty however. As development of the mammary gland progresses, so do the varying roles for these hormones. 


\subsubsection{Development During Pregnancy}

Gestational hormones stimulate further proliferation of the epithelium and ductal system in the pregnant dam. In mouse mammary development the presence of estrogen and its binding to nuclear ER- $\alpha$ is required for ductal morphogenesis, while progesterone acts through RANK in the same manner as side-branching during puberty to induce tertiary branching and alveolar development during pregnancy (Stingl, 2011; Asselin-Labat, 2010). In mice, alveoli, the hollow sacks lined with secretory mammary epithelium at the termini of duct branches, are organized into clusters by day 16.5 of pregnancy (about $3 / 4$ of gestation period) but do not undergo functional differentiation, or lactogenesis of the mammary epithelium until the end of pregnancy, around parturition (Brisken, 2006). Milk components synthesized by the epithelial cells collect in the alveoli towards late pregnancy and alveoli dilate and grow due to increased pressure. A distinct drop in progesterone at parturition signals the secretion of milk components into the alveoli. Oxytocin binding its receptors on the myoepithelium causes a contraction, which squeezes the swollen alveoli pushing milk out through narrow ducts towards storage sinuses (Rudolph, 2011; Lollivier, 2006). When oxytocin binds receptors on the luminal epithelial layer of the alveoli, the effect is the acceleration of intracellular secretion of casein milk proteins prior to myoepithelial contraction (Lollivier, 2006). Oxytocin in a neuro-polypeptide hormone produced and secreted by the posterior pituitary gland under many circumstances, one of which being parturition. 
Prolactin is a pituitary polypeptide hormone detected in pregnant and lactating mammals and has a tendency to spike dramatically just before parturition, playing a major role in the second stage of lactogenesis (Tucker, 1981). A total deletion of the prolactin gene in mice renders females infertile (Gallego, 2001) and without prolactin signaling within the mammary epithelium alveogenesis will be incomplete and secretory differentiation will fail to occur (Brisken, 2006). Prolactin is the major controller of lactogenic differentiation, but it is supported synergistically by metabolic hormones such as growth hormone, placental lactogen and adrenocorticotropin to promote milk synthesis and secretion (Tucker, 1981). During lactation, prolactin is associated with cell survival, glucose metabolism, and MEC-specific lipogenesis and beta-casein expression (Rudolph, 2011). More recent evidence suggests that the mammary gland itself has capabilities to secrete and respond to paracrine and autocrine prolactin, growth hormone, leptin and parathyroid hormone related peptide (Brisken, 2006). The prolactin receptor (PRLR) signal cascade involves the JAK2/STAT5 pathway, resulting in the activation of several transcription factors (including ELF5), which are related to the functional differentiation of the mammary gland (Brisken, 2006). Outside of the mammary gland, PRLR activation on pancreatic beta-islet cells causes proliferation and insulin secretion, which is related to metabolic shifts required for milk production (Brisken, 2006).

There are species related differences in prolactin response. For example, as ruminant breeding is closely associated with seasonal day-length, or "photoperiod", a positive effect relationship has been observed in heifers between extended photoperiods and elevated prolactin secretion. Specifically, cows that calve in the fall had higher measured 
prolactin levels mid-pregnancy than cows that calved in the spring (Knight, 2001). However, this significant difference in prolactin level during gestation does not necessarily correlate to an increase in mammogenesis as in vitro studies have not shown a mitogenic effect of prolactin on bovine mammary cells in culture (Knight, 2001).

In swine, the effects of prolactin are most crucial for mammary gland growth between days 90 and 109 of a 115 day pregnancy even though the endometrium and placenta do not secrete prolactin or placental lactogen as is observed in other species (Trott, 2009). Administration of additional prolactin to sows did not contribute to further development of the mammary gland, or increased nursing piglet weight leading researchers to believe existing prolactin receptors (PRLR) are saturated with the naturally occurring prolactin ligand concentration. These findings indicate the prolactin receptor as the limiting factor on the effects of prolactin rather than the abundance of the hormone itself (Trott, 2009).

The PRLR does not only interact with prolactin, but also binds growth hormone (Xu, 2011). Both PRLR and GHR are transmembrane glycoproteins and members of the cytokine receptor superfamily of G-coupled protein receptors and are highly conserved across species (Xu, 2011). While GH has the ability to bind both receptor types, prolactin only binds the PRLR. Both GH and prolactin play crucial roles in the mammary gland from development through lactation.

Growth hormone $(\mathrm{GH})$, or somatotropin, is a polypeptide hormone synthesized and secreted mostly by the anterior pituitary somatotroph into the peripheral circulation, 
although more recent evidence suggests other cell types may secrete trace levels for autocrine or paracrine signaling (Moffat, 1999). Secretion of GH by the pituitary is regulated by peptides of hypothalamic origin. Growth hormone-releasing factor (GHRF) is known to stimulate GH secretion while somatostatin inhibits secretion (Etherton, 1998). GH is made up of 191 amino acids, however, there are species differences and even breed differences in amino acid sequence and subsequent structure that make the GH of one species biologically inactive in another species due to receptor affinities (Etherton, 1998).

While GH has many direct targets, such as muscle and bone, where it contributes to growth as its name suggests, its indirect effects are more widespread when GH acts as a signal for insulin-like growth factor 1 (IGF-1) secretion. Most systemic IGF-1 originates in the liver as it is synthesized and secreted into the blood in response to GH. This relationship between GH and IGF-1 is termed the "somatotropic axis" (Raccurt, 2002). Some cell types, including those within the mammary gland, can synthesize either or both GH and IGF-1 locally, possibly due to reliance upon these growth factors for development and function.

IGF-I bioavailability and activity is regulated by insulin-like growth factor binding proteins (IGFBP) through reservoir-type storage by extending the half-life of the hormone or directing binding to specific tissue sites. Six high-affinity binding proteins have been identified and the majority of circulating IGF-I in vivo is bound to IGFBP3, IGFBP4 or IGFBP5 (Elis, 2011; Berry, 2001). The differing forms of IGFBP may play 
distinct roles in mammary development and involution (Berry, 2001). Levels of IGFBPs have been demonstrated to vary based on hormonal changes in serum due to exercise, diet, pregnancy and age (Elis, 2011).

Growth hormone has long been thought to act indirectly through IGF-1 signaling to induce the elongation of ductal branches in the mammary gland as well as contribute to the proliferation and differentiation of terminal end buds during puberty (Perry, 2008). GH-null rats and GHR-null mice have both previously been shown to undergo impaired mammary development in comparison to respective wild-types (Mukhina, 2006; Perry, 2008). This effect has been supported by one study that antagonized the natural GH signal resulting in impaired mammary development in mice, and the rescue of mammary development in GH-null rats by administering exogenous GH (Perry, 2008). These studies indicate a necessary relationship between GH and the proliferation stage of the mammary gland although the authors did not determine whether or not there may be a direct relationship versus mediation by IGF-1 alone.

With a structure very similar to growth hormone, placental lactogen (a.k.a chorionic somatomammotropin) is secreted by the placenta and is known to stimulate lipolysis and antagonize insulin action allowing for more energy availability for the fetus while contributing to mammary development during pregnancy (Picciano, 2003).

At the end of pregnancy, the normal mammary gland has undergone all preparation to feed the growing offspring, and the act of parturition itself and the suckling of new young 
both contribute to the ejection of stored milk. The specifics of which will be explored further in the following section. 


\subsection{Lactogenesis}

\subsubsection{Overview}

Although the composition of milk varies depending on a variety of factors including species, breed, individual and even milking event, milk is generally made up of water containing lipids, proteins, amino acids, vitamins, minerals, immunoglobulins, hormones, cytokines, enzymes and other peptides essential for the growth of mammalian young (Haug, 2007). While lactose and most minerals are water soluble, lipids exit the cell emulsified in coated globules and milk proteins are suspeneded in micelles with calcium or salts (Haug, 2007). Early mammary secretion (first 3-5 days post partum in humans) is termed "colostrum", a viscous substance rich in minerals, antibodies and other immune factors including lactoferrin and secretory immunoglobulin A (Picciano, 2003). White blood cells and specifically $\mathrm{B}$ and $\mathrm{T}$ lymphocytes within colostrum and mature milk contribute significantly to building the immune system of the neonate (Larson, 1979). As colostrum transitions to mature milk, there is a decrease in mineral and protein content and an increase in water and lactose (Picciano, 2003).

Major differences between ruminant and non-ruminant milk production are due in part to the dietary differences between species and the contribution of gastrointestinal flora to the circulating nutrient pool available to the mammary gland for milk synthesis. While most ruminants naturally consume large quantities of feed high in cellulosic, indigestible fiber, microbe populations maintained within the anaerobic rumen environment ferment 
these carbohydrates into volatile fatty acids (VFA) which are absorbed by the host ruminant. As microbes expire they are digested by the animal providing an additional source of protein to be absorbed in the gastro intestinal (GI) tract (Van Soest, 1994). In general, ruminant animals maintain much lower levels of circulating glucose compared to non-ruminants due to this dietary process and therefore use VFAs as an alternative form of energy wherever possible. For example, during late gestation $55 \%$ of ruminant fetal energy is taken up as amino acids while only 30-35\% is supplied by glucose (and subsequent metabolite, lactate) (Bell, 2000). The remaining energy is supplied in the form of acetate. Depending on their diet, rodents and other hind-gut fermenters, also have the ability to absorb VFAs produced through the activity of caecal microbe populations and may also contribute microbial VFAs to milk synthesis (Morishita, 1996).

High-yielding dairy cows ingest less energy than they expend at the start of milk production, classifying this state as a negative-energy-balance (Kuhla, 2011). Consequently, they must mobilize fat, glycogen, and muscle protein to meet energy output requirements and the breakdown of skeletal muscle becomes the primary source for essential amino acids (EAAs). Loss of body protein in early lactation may amount to approximately $20 \mathrm{~kg}$ per day in some dairy cows (Kuhla, 2011). It has been suggested that the free AAs in circulation due to skeletal muscle breakdown may trigger a loss of appetite, even in a state of negative energy balance. Feed intake in dairy cattle decreases as they approach parturition, and only slowly increases to finally reach a state of positiveenergy-balance after 8 to 12 weeks of lactation (Bauman, 2000). 
Rodents on the other hand experience a gradual increase in the lactational demands of nursing pups, and so feed intake is gradually increased proportionally to the growth and number of pups. This increase can be up to $300-400 \%$ compared to feed intake prior to pregnancy and lactation, but can meet the nutritional requirements for the output without requiring the loss of body stores as observed in ruminant species (Bauman, 2000). Human young demand a comparatively modest volume of milk for adequate nutrition when compared to other mammalian species; normal human lactation should rarely result in a negative-energy-balance (Bauman, 2000).

On the cellular level however, milk ejection is rather similar between species. Cuboidal, secretory epithelial cells form the closest contact possible between adjacent cells, which are termed tight junctions. Tight junctions function both as a barrier and as a gate, as during lactation they mediate the transport of small molecules and ions between cells while maintaining polarity within the cells for the maintenance of ion pumps and channels (Delamaire, 2006). Ejection of milk components from the epithelium is a result of osmotic pressure build-up as lactose and other minerals accumulate, drawing additional water into the cells. There are gap junctions between adjacent cells that may allow for some exchange of small molecular signal proteins, contributing to the synchronized ejection of milk components from the epithelium into the lumen of the alveolus (Larson, 1979).

As milking decreases, or weaning occurs, the composition of milk contains fewer nutrients than milk from earlier lactation (Delamaire, 2006). This gradual change is 
caused by the "loosening" of the tight junctions allowing for greater permeability and a decreased uptake of milk precursors by epithelial cells. The synthesis of individual milk constituents will be discussed further within this review. 


\subsubsection{Protein Synthesis}

A crucial component of milk for the growth and survival of young is the supply of amino acids, minerals and antibodies delivered by milk proteins. The majority of milk protein consists of four casein proteins $\left(\alpha-s_{1}, \alpha-s_{2}, \beta\right.$ and $\left.\kappa\right)$ and whey proteins ( $\alpha$-lactalbumin and $\beta$-lactoglobulin). Although less abundant, milk also contains transferrin and lactoferrin, immunoglobulin IgA, lysozyme, and serum albumin (Jenness, 1979). Bovine milk is widely commercialized as a nutritious food source for human consumption and contains an average of $32 \mathrm{~g}$ of protein per liter, $80 \%$ of which is casein. Casein forms micelles with calcium and phosphorus for efficient transport of these minerals to the digestive system once ingested (Haug, 2007). The most abundant casein protein in human breast milk is homologous with the bovine milk protein beta-casein (Jenness, 1979).

Blood proteins and milk protein precursors (i.e. amino acids) enter the secretory, lobular mammary epithelial cells through the basal membrane, which is in direct contact with the basement membrane of the extracellular matrix separating the epithelium from the blood stream (Larson, 1979). Milk proteins are coded for by messenger RNA (mRNA) exported from the nucleus and capped on the 5' end. At the 3' end of milk protein mRNA there is a tail of multiple adenylyl nucleotides (a "poly (A)-tail"), which aids in translation and protects against mRNA degradation (Rhoads, 2007). Each set of 3 nucleotides codes for an individual amino acid, which is recruited to the ribosome bound to a complementary transfer RNA (tRNA). The ribosome translates mRNA into peptide chains of amino acids on the endoplasmic reticulum. From here, long, polypeptide chains are transported to the 
Golgi apparatus where glycosylation and phosphorylation occur along with the coupling of calcium to casein micelles. Tertiary folding and accumulation of micelle structure is completed before fully formed milk proteins are ejected through the apical membrane of the epithelial cell into the lumen of the alveolus through transport by secretory vesicles (Larson, 1979).

Lactogenic hormones (prolactin, insulin, glucocorticoids) have great control over the regulation protein synthesis by the mammary gland not only by stimulating transcription of mRNA coding for milk protein genes, but also by stabilizing mRNA and extending the half-life for more efficient translation (Rhoads, 2007). The translation of milk proteins is then stimulated by a synergy between available amino acids and insulin and prolactin signaling (Rhoads, 2007). In the presence of lactogenic hormones, the mammary epithelial cell selectively polyadenylates milk protein mRNA in the cytoplasm elongating the poly(A)-tail for enhanced translation (Rhoads, 2007).

The availability of amino acids to the mammary gland for milk synthesis is based primarily on dietary intake, but also gastrointestinal and hepatic utilization of amino acids (Bequette, 1997). During lactation, ruminants specifically experience a surprisingly low efficiency of dietary amino acid conversion to milk protein. In fact, the levels of certain free-form essential amino acids (EAA) absorbed from the circulation by the mammary gland have been measured to be insufficient for the amount of milk protein secreted. This deficiency must be met by breaking down formed proteins that contain the necessary EAAs, sometimes sacrificing muscle tissue (Bequette, 1997). Other amino acids, whose 
absorption is greater than output as milk protein --leucine is an example-- are not taken from protein-bound sources (Bequette, 1997). When additional free-form dietary amino acids are administered, the mammary gland has a higher affinity for these sources than the protein-bound sources, which require extra energy to break down. This illustrates the adaptability of the gland to changes in supply and demand. 


\subsubsection{Lactose Synthesis}

The disaccharide lactose is the main osmotic agent drawing water into milk and due to this, lactose synthesis contributes significantly to milk yield. Lactose is the most abundant carbohydrate found in milk contributing nearly half of the caloric content required by the infant and synthesized from glucose and galactose within the Golgi apparatus (Sunehag, 2003; Anderson 2007). The synthesis of this particular sugar is unique to the mammary epithelial cell due to the expression and activity of lactose synthetase, a heterodimer made from milk protein alpha-lactalbumin and its interaction with Golgi-bound glycosyltransferase beta-1,4-galactosyltransferase (Anderson, 2007; Shaper, 1998). In dairy cattle, 55-70\% of glucose taken up by the mammary gland is used for the synthesis of lactose (Guinard-Flament, 2006). Eighty to $85 \%$ of the carbon in bovine milk lactose is derived from glucose because more than half of the galactose required for lactose synthesis is actually a converted product of glycolysis. This production involves conversion of glucose 6-phosphate to galactose by the enzymes glucose phosphorylase and glucose 4 epimerase (Sunehag, 2003). Additional galactose can be synthesized from glycerol, and some studies suggest the lactating mammary gland has the enzymatic capacity to produce glucose-6-phosphate from other 3-carbon substrates, a process characterized within the human breast and termed hexoneogenesis (Sunehag 2003). The percentage of plasma glucose-derived lactose is higher in nonruminants with greater dietary glucose intake and during a fed state as opposed to fasting (Anderson, 2007). 
Glucose pays a critical role in lactation for both ruminants and non-ruminants although the availability of glucose to the gastrointestinal tract, and subsequently the circulation, is much lower in the ruminant due to rumen fermentation. In addition, the fate of glucose in the mammary epithelial cell differs slightly between the two mammalian metabolic systems. Overall, this monosaccharide is necessary for the synthesis of lactose, metabolic energy (ATP production), glycerol production for de novo fatty acid synthesis, and NADPH production through the pentose phosphate pathway (Van Soest, 1994; GuinardFlament, 2006). Additionally in non-ruminants, glucose is the main precursor fatty acid synthesis as will be discussed in chapter 1.3.4.

Because the mammary epithelium does not possess the necessary enzymes for gluconeogenesis, all glucose utilized by this organ must be taken up from the circulation. Glucose enters the mammary epithelial cell via the GLUT1 transporter, an insulin independent transporter. In dairy cows, the mammary gland has been known to use up to $85 \%$ of total circulating glucose, although published research states that the GLUT1 transporters on ruminant mammary epithelial cells are probably never saturated under normal physiological conditions (Zhao, 1996). Once inside the cell, if directed towards use as an energy source, glucose is converted to glucose-6-phosphate by the enzyme hexokinase (Rudolph, 2011; Salway, 1994). From this point, glucose-6-phosphate can be a precursor for either glycolysis and the tricarboxylic acid cycle (TCA) or the pentose phosphate pathway providing energy for fatty acid synthesis. 


\subsubsection{Lipid Synthesis}

Although "reduced-fat" and "non-fat" dairy products have increased in popularity for the adult human consumer, the neonate would not survive without milk fat. The concentration of fat in milk varies between species and the needs of their young, but on average, $95-98 \%$ of the lipid content in milk is triacylglycerols made up of fatty acids of differing lengths and levels of saturation (Haug, 2007). The remaining 2-5\% of lipids are made up of diacylglycerol, cholesterol, phospholipids and free fatty acids (Haug, 2007). Triacylglycerol is synthesized by the joining of long or short chain fatty acids to a glycerol backbone. Once a molecule is complete it combines with other fully-formed TAG to make lipid globules that increase in size as they are translocated to the apical surface of the epithelial cell where they are surrounded by the apical membrane which is pinched off and emulsified in milk (Larson, 1979). Milk fat can be made from fatty acids stored in adipose tissue, diet, or through de novo synthesis and carried through the circulation to the mammary epithelium bound to albumin or very low-density lipoproteins (VLDL). Ruminant milk is unique in that it contains a high proportion of short-chain (between 4 and 10 carbons) fatty acids even though these forms are not found in non-ruminant milk or feed. This means ruminant milk fat is more often derived from de novo synthesis or the desaturation of free long-chain fatty acids (Bauman, 2011). In the non-ruminant mammal, glucose is the primary source of both glycerol and fatty acid synthesis (Anderson, 2007).

Lipogenesis, or more specifically, de novo synthesis of fatty acids occurs mainly in the 
liver, adipose tissue and mammary gland of a lactating mammal (Laliotis, 2010). The main precursor for this pathway is acetyl-coA, however, the source of acetyl-coA and the primary location of lipogenesis is species specific. In humans, and most non-ruminant animals, the majority of fatty acid synthesis occurs in the liver. Conversely, the lowglucose ruminant diet causes the ruminant to rely on the liver primarily for its gluconeogenic capabilities, and the adipose tissue and mammary gland (during lactation) are the sites, for the majority of de novo fatty acid synthesis (Laliotis, 2010). The main energy sources delivered to the gut post-fermentation by the rumen are the volatile fatty acids (VFA) acetate, propionate, and butyrate. Acetate is the basic building block for fatty acid synthesis in ruminants, which requires NADPH as a reducing agent (Bauman, 2011).

As illustrated in figure 1, non-ruminants can utilize glucose for fatty acid synthesis. Acetate and pyruvate can be oxidized to acetyl-coA within the mitochondria and converted to citrate in order to be transported out of the mitochondria by the citrate/tricarboxylate carrier (CiC). Through the action of citrate lyase, citrate can be broken down into acetyl-coA and oxaloacetate outside of the mitochondria. Acetyl CoA may then be used for fatty acid synthesis and oxaloacetate can then be converted to malate and cycled back to pyruvate through the action of malate dehydrogenase. The reaction producing pyruvate from malate provides an additional source of NAPDH for the non-ruminant, but as illustrated in figure $2 a$, this enzyme is not active in the ruminant mammary epithelial cell. 
Another difference in the ability of ruminant mammary epithelial cells to produce NADPH is the lack of citrate lyase activity. As illustrated in figure $2 b$, citrate cannot be converted to acetyl CoA or oxaloactetate, and therefore, there is no complete pyruvate/malate cycle. Due to this factor, the TCA cycle cannot contribute to fatty acid synthesis in the ruminant and NADPH must be produced by isocitrate dehydrogenase (IDH) activity and the conversion of isocitrate to alpha-ketoglutarate in the cytosol or by the pentose phosphate pathway (Salway, 1994). 
Figure 1. Fatty Acid Synthesis

This figure illustrates the alternate pathways and carbon sources utilized by ruminant versus non-ruminant animals for eventual participation in de novo fatty acid synthesis within the mammary epithelial cell.

\section{Fatty Acid Synthesis Precursors}

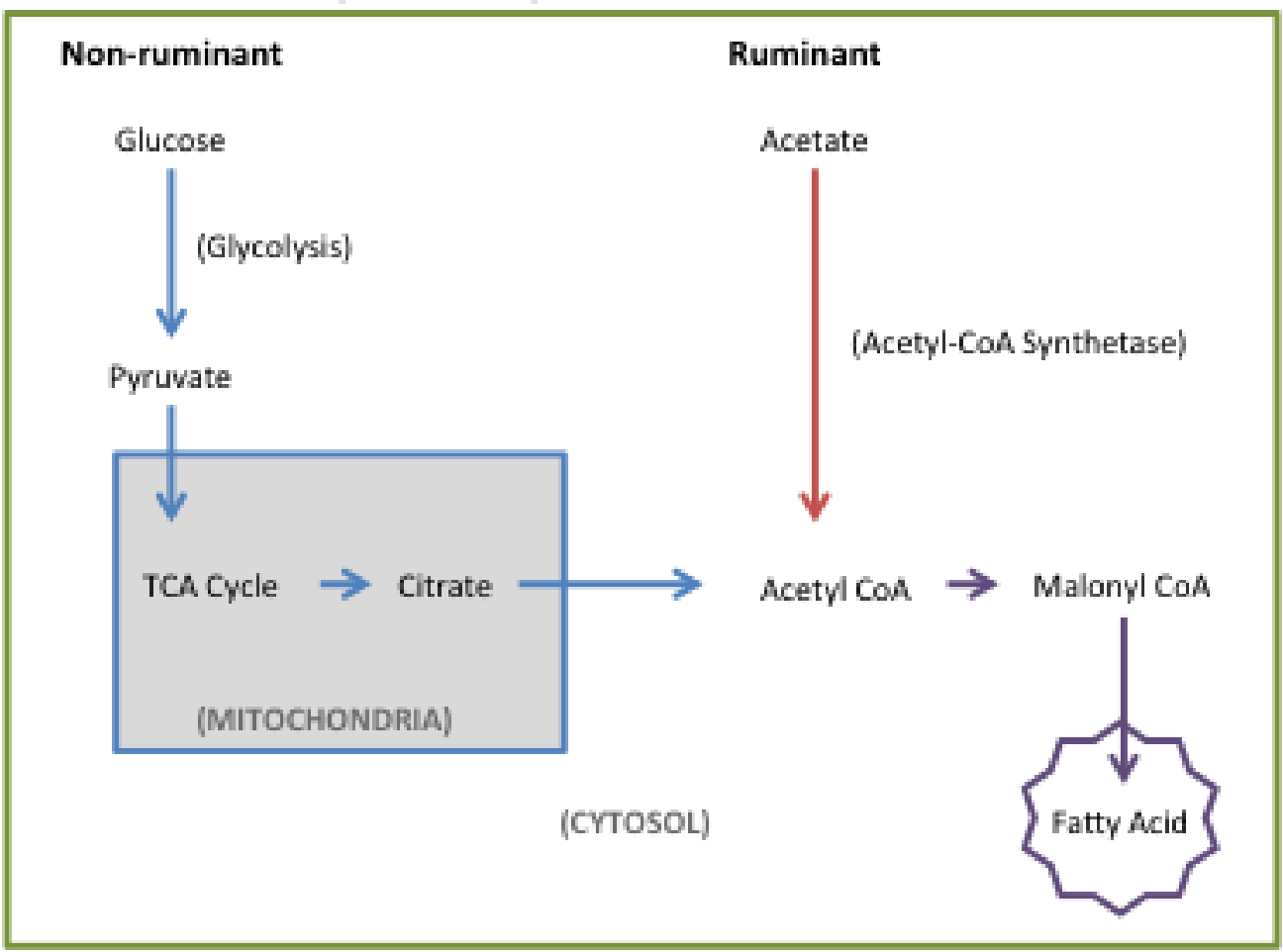


Figure 2. NADPH Production

NADPH is produced through the action of the pentose phosphate pathway, malate dehydrogenase and isocitrate dehydrogenase, in the non- ruminant mammary epithelial cell. Ruminant animals do not express the enzymes necessary for all of these reactions; as illustrated in the bottom figure with crossed-out and shaded boxes, most NADPH in the ruminant mammary epithelial cell must be produced via isocitrate dehydrogenase activity and to a lesser degree, the pentose phosphate pathway.

a.

\section{Non-ruminant NADPH Production}

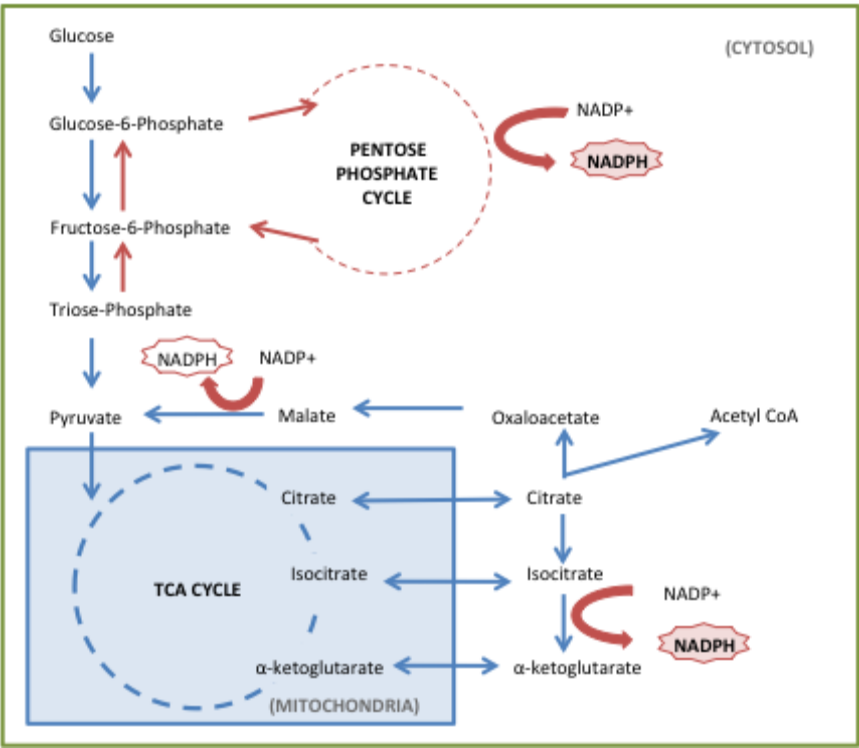

b.

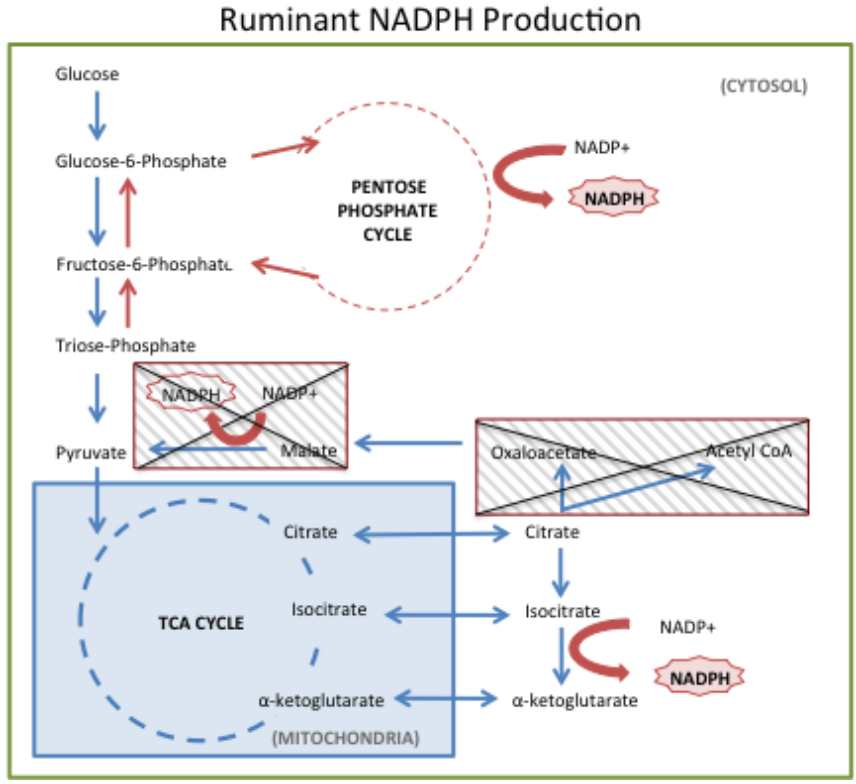




\subsubsection{Pentose Phosphate Pathway}

The pentose phosphate pathway is active only in the liver, adipose, lactating mammary gland, adrenal cortex and red blood cells in the mammal (Mellenberger, 2009). When glucose is present in abundance and glycogen stores are full, excess glucose will be stored as fat; a process which requires the products of the pentose phosphate pathway. Mammary epithelial cells must also take advantage of this pathway when demand for milk fat becomes a metabolic priority during lactation (Salway, 1994). The pentose phosphate pathway produces NADPH, which can be used for biosynthesis of fatty acids and cholesterol.

Glucose 6-phosphate enters the pentose phosphate pathway and is oxidized by glucose-6phosphate dehydrogenase to form 6-phosphoglucono-delta-lactone and NADPH. Lactonase further hydrolyses the product into 6-phosphogluconate, which is oxidized by 6-phosphogluconate dehydrogenase to ribulose 5-phosphate and gives off $\mathrm{CO}_{2}$ and an additional NADPH. This phase of the pathway is irreversible, the final product, ribose 5phosphate, can accumulate, and three molecules of ribose 5-phosphate be converted into two molecules of fructose 6-phosphate and one molecule glyceraldehyde 3-phosphate. Fructose 6-phosphate can be converted back to glucose 6-phosphate for re-entry into the pentose phosphate pathway cyclically or re-entry to the glycolytic pathway. This pathway is regulated by the availability of NADP+, which is readily abundant during fatty acid synthesis, where NADPH is reduced (Mellenberger, 2009). Ruminant mammary tissue only undergoes an increase in pentose phosphate activity of about 3 fold, while pentose 
phosphate activity in rodent mammary glands has been shown to increase by $15-80$ fold (Mellenberger, 2009). This is probably due to glucose being the substrate upon which this pathway relies, and the relatively low levels of circulating glucose in the ruminant system. 


\subsection{Mammary Gland Models}

Due to the endless complexity of a whole animal system, in vitro modeling has become the preeminant approach to studying cellular function in a controlled manner that can be manipulated experimentally (Matitashvili, 1997). Among the most commonly employed mammary models are explant tissue, primary cell and immortal cell line cultures. 


\subsubsection{Explant Culture}

An explant culture consists of a small, three-dimensional tissue-sample that may be excised from the mammary gland through biopsy or immediately following slaughter. As a model, the explant is an excellent way to observe the interactions between all of the cell types within the gland that may depend on structural relationships to function similarly to in vivo (Keys, 1997). In addition, an effect observed in vivo can be validated in culture when that tissue is separated from circulating ligands and systemic signals (Telang, 1989). Some drawbacks to explant culture (excluding xenografts) are: (a) the short life of the tissue in culture as they are only viable for a few day at most (Keys, 1997); (b) the mix of cell types within an explant, making study of the epithelium exclusively impossible, and knowing the proportion of epithelial cells in the explant is a challenge; (c) explants cannot be frozen cryogenically, so some experiments are not repeatable over time with samples from a single isolation event. While explants from rodent mammary glands have been used in experiments for over 50 years, conducting successful explant studies with ruminant mammary tissue has presented a much greater challenge, and is more narrowly studied (Matitashvili, 1997). 


\subsubsection{Primary Cells}

Primary cell cultures consist of a specific cell type isolated from tissue that may be excised from an animal under the same conditions as an explant. Once tissue is excised it can be minced, digested and strained to a single cell suspension, at which point differing cell types can be separated through a variety of protocols including gradient cetrifugation or plate adhesion incubation periods (Smalley, 2010). Primary cells can be isolated from animals in different stages of development (i.e. pregnancy versus lactation) to control for differences based on starting stage of the mammary cell (Matitashvili, 1997). Other advantages to using primary cell culture are: (a) the ability to study a single cell type; (b) primary cells secrete proteins and lipids directly into media which can then be measured quantitatively; (c) primary cells can proliferate for a greater volume of samples and can be kept in culture for extended periods provided the right combination of growth factors and nutrients; (d) primary cells can be cryogenically frozen and used for future research or to repeat an experiment at a later time, even with cells isolated from the same animal (Keys, 1997). A few drawbacks are: (a) the necessity for validation that the intended cell type was indeed the one isolated and cultured and the likelihood of a small percentage of contaminating mesenchymal cells (Matitashvili, 1997); (b) an environment unlike the in vivo environment, cryopreservation and extended passaging of cells may cause a change in the cells morphology and function (Keys, 1997). Morphology and secretory activity may also be affected by whether primary cells are plated on plastic culture dishes, artificial extracellular matrices, or attached collagen gel (Matitashvili, 1997). 


\subsubsection{Immortal Cell Lines}

An alternative to these methods is the culture of an immortalized mammary cell line. Several mammary epithelial cell lines from a variety of species have been used in mammary biology research and all originate from primary cell isolation of normal or tumor cell types (Matitashvili, 1997).

Commonly studied are immortal mammary epithelial cell lines that originate from murine species. The COMMA-1D cell line, for example, has been used extensively in mammary gland reasearch and was initially isolated from mid-pregnant BALB/c mice. Although this line has been passaged continuously, it was never transformed and the mechanism behind its immortality is somewhat unknown, even by scientists who initially characterized the line (Danielson, 1984). These cells were assumed to be proginator cells, or stem cells and due to their ability to populate a cleared fat pad with a normal mammary structure as well as their inducible casein production in vitro they are considered an excellent in vitro model for the mouse mammary epithelium (Danielson, 1984). The HC11 cell clone was later isolated from the COMMA-1D line due to the need for a strain that would grow without an extracellular matrix or co-cultivation with other cell types. The success of this isolation was confirmed through the expression of betacasein dependent upon treatment with prolactin when cultured on plastic (Ball, 1988).

Although there are many established cell lines that originate from mice, fewer lines are readily available for bovine studies. One cell line, MAC-T, was developed by Huynh et 
al. through the stable transfection of alveolar epithelial cells from a mid-pregnant Holstein heifer with the simian virus (SV)-40 large T anigen (TAg) (Huynh, 1991). The SV-40 TAg is an oncoprotein (cancer causing protein) that inhibits the activity of tumor suppressing factors p53 and retinoblastoma allowing the host cells to proliferate indefinitely (Ali, 2001). MAC-T cells have the ability to differentiate to a "lactating" phenotype when induced with a lactation medium including dexamethazone, insulin and prolactin, defined by the fact that they can secrete milk proteins in culture (Huynh, 1991). 


\subsection{Lactation \& Breast Cancer}

Breast cancer accounts for 1 in 4 female cancers and is by far the most common cancer in women worldwide with rising incidence (Siewit, 2009; Moreira, 2010). Epidemiological studies have recognized a relationship between early age of first full-term pregnancy and total number of pregnancies with a reduced risk of breast cancer for nearly a half-century (MacMahon, 1970). More recently, the relationship between mammary gland development, lactation and its subsequent preventative effects are being studied in clinical settings (Yogi, 2012). Although the post-lactational breast regresses to a state very similar to the nulliparous breast, studies have shown that pregnancy induces some permanent changes in gene expression within the mammary gland, specifically related to DNA damage repair, enhanced immunity, and decreased cell proliferation (Russo, 2005; Yogi, 2012). The end of lactation signals a regression of the functional gland that includes massive apoptosis leaving just a few stem cells to repopulate the gland upon future pregnancy. These parous stem cells have been exposed to different hormones and structural changes, making them epigenetically different and functionally different than the stem cells populating the mammary gland during first pregnancy (Russo, 2005). Additionally, mouse studies have shown that an early pregnancy can reduce the total

number of stem cells within the mammary gland without impairing their ability to repopulate the gland (Visvader, 2009). 


\subsubsection{Breast Cancer Biomarkers}

Early detection and classification of breast cancer greatly improves the odds of the survival of a patient, which makes the simplicity of screening and the identification of biomarkers extremely important (Ou, 2008). The term "biomarker" is described by the National Institute of Health as a cellular event in which expression signifies a specific phenotype, in this case, cancer (NIH, 2011). Interestingly, transcription factor GATA-3 has been implicated as a gene driving luminal cell differentiation within the mammary epithelium and expression of GATA-3 is also a biomarker and a determinant of breast cancer patient prognosis (Visvader, 2009). With higher levels of Gata-3 a tumor is more likely to respond to treatment as it is associated with a more differentiated state and is less likely to metastasize.

There are numerous ways in which biomarkers may be identified and each methodology has both strengths and limitations. Methods based on existing hypotheses tend to favor a narrower scope, focusing on a specific pathway thought to be affected by a carcinogenic introduction. For example, many tumor cells exhibit the "Warburg effect" or the heightened consumption of glucose causing a build-up of lactate through anerobic gycolysis and reduced use of the TCA cycle (Levine, 2010). Since its discovery in 1926, this pathway has been compared between tumor cells and normal cells of the same tissue to implicate a few oncogenes and tumor-suppressing genes. A deeper understanding of these genes implicated may be useful in developing targeted gene therapies in cancer treatment (Levine, 2010). A major drawback to studying this narrow scope of genes on 
the transcriptional level is the lack of correlation between gene expression and protein expression, with recorded differences as high as 30 -fold (Ou, 2008). Additionally, there are post-translational modifications and cellular localization events that totally change the function of a molecule, which are not detected by quantitative mRNA expression profiles. An alternative method is to employ a discovery technology or hypothesis-generating approach such as proteomics, the results of which can be compared with transcriptional data to implicate specific genetic biomarkers. 


\subsection{Summary}

The exocrine mammary gland is an organ of great complexity with a synchronous relationship to endocrinology and metabolism. It is this systemic involvement makes this organ, and the cells of which it is comprised quite difficult to study exclusively, yet a deeper understanding may provide insight into the treatment and prevention of cancer and the nutritional optimization and production efficiency of the dairy industry. Instead of approaching the holes in our knowledge of this gland by focusing on the pathways we already expect to be involved, research into development of the mammary gland may benefit from a more global approach. As "omic" technologies are improving rapidly, and transcript and protein databases are expanding with new research, our lab has developed a curiosity in the application of these technologies to gain further knowledge on differentiation of the mammary epithelium.

Through the application of literature review to our experimental analysis, we hope to provide novel insight into cellular mechanisms that may be involved in the differentiation of mammary epithelial cells from a proliferation stage to lactation. Moreover, we hope to approach this question by taking into consideration the whole-animal species differences, from diet and metabolism to needs of the young that may be applicable to the developing mammary epithelial cell. 
CHAPTER 2 - Proteomic Analysis of Differentiation in the MAC-T Cell Line

\subsection{Introduction}

Previous research within our lab has demonstrated an effect of growth hormone (GH) on the proteomic profile of differentiated bovine mammary epithelial cells (MEC) of the immortal cell line MAC-T ${ }^{*}$. MAC-T cells can be differentiated in vitro through treatment with a classic lactation medium containing dexamethosone, insulin and prolactin at the point of confluence (when cells completely coat the surface upon which they are plated) and are known to retain many of the characteristics of bovine MEC (Huynh, 1991). The proteins that changed in response to GH treatment were related to glucose metabolism, NADPH production, cytoskeletal changes and RNA processing which led us to believe the effect of GH may cause changes that are similar to those which occur during differentiation events. If true, $\mathrm{GH}$ would be implicated as a possible factor in mammary epithelial cell differentiation, which contradicts current dogma of the role of GH within the mammary gland (Zhou, 2008).

In order to assess the results of the GH study and its association with differentiation, there must be a control study with which to compare. The obvious control is to observe changes in global protein expression that occur within the epithelium over the process of differentiation in MAC-T without growth hormone treatment. We went about this observation by comparing protein extracts isolated from cells still proliferating in vitro

\footnotetext{
* Thesis research by Tasha Johnson, 2010. Publication in progress.
} 
and cells that had been differentiated to a "lactating" phenotype for a period of 7 days. Although there have been previous attempts to develop protein expression profiles for a "normal" mammary epithelial cell, few have considered the global changes that occur throughout the process of differentiation (Desrivieres, 2003). There are likely major differences, to be considered as well, between protein expression in human and murine MEC versus those of ruminant (specifically bovine) origin as there are major differences in metabolism, fat storage, and milk synthesis between the species (Van Soest, 1994).

Proteomics is a discovery-based approach to molecular biology. By refraining from attempting to quantify expected genes or proteins, proteomics allow us to draw back the focus and identify total protein expression from a sample. From this point, we may compare across samples from different treatments or developmental stages to create new hypotheses for the molecular events taking place at the time of protein isolation. In this way, unexpected discoveries may be made that can later be expanded upon and validated through fine-tuned quantitative technologies. Transcriptomic technologies are highly valuable in that they provide a wider array of genes on which to base hypotheses, however, there is a high probability that many genes transcribed are never translated in vivo (Ou, 2008). While a combination of both assay types would amount to a more complex picture, the proteome depicts actual protein existence rather than relying on assumptions based upon presence of mRNA alone, which is why we selected this approach specifically. 
In this study, total protein was extracted from MAC-T cells during cell proliferation or after seven days of differentiation, which should theoretically correspond with established lactation in vivo, as this was the treatment period in the former study upon which this experiment was based. Global protein expression was then visualized by twodimensional gel electrophoresis (2DGE) before identification of individual proteins that changed significantly in abundance through matrix assisted laser desorption/ionizationtime of flight (MALDI-TOF/TOF) tandem mass spectrometry. 
2.2 Methods

All reagents were acquired from Sigma Aldrich (St. Louis, MO) unless otherwise noted. 


\subsubsection{Cell Culture}

MAC-T cells were cultured on $10 \mathrm{~cm}$ plastic plates under growth medium (low glucose Dulbecco's Modified Eagle Medium with 10\% FBS, 1\% Penicillin/Streptomycin (PS), $1 \%$ Amphotericin B, $5 \mathrm{ug} / \mathrm{mL}$ insulin, $1 \mathrm{ug} / \mathrm{ml}$ progesterone), which was replenished every 48 hours until confluence at which point half of the plates were harvested for protein extraction. Differentiation was induced in the remaining plates with lactation media (low glucose Dulbecco's Modified Eagle Medium with 10\% FBS, 1\% PS, 1\% Amphotericin $\mathrm{B}, 1 \mathrm{ug} / \mathrm{mL}$ dexamethasone, $5 \mathrm{ug} / \mathrm{mL}$ insulin, $5 \mathrm{ug} / \mathrm{mL}$ prolactin). Differentiated cells were cultured in lactation media replenished every 24 hours for an additional 7 days before harvest. 


\subsubsection{Protein Extraction}

Media was aspirated from all plates followed by a $1 \mathrm{ml}$ rinse of sterile filtered phosphate buffered saline solution (PBS). Cells from nine $10 \mathrm{~cm}$ plates were pooled into three microfuge tubes ( $\mathrm{n}=3,3$ plates per $2 \mathrm{ml}$ tube). Cells were rinsed again with PBS by vortex and centrifugation. Cells were lysed in $450 \mathrm{ul}$ lysis buffer (7M urea, $2 \mathrm{M}$ thiourea, 1\%ASB-14, 40mM tris base, $0.1 \%$ IPG buffer and 40mM DTT) followed by three 10second pulses of sonication with a probe sonicator while microfuge tubes remained on ice. Lysed cells were centrifuged at $4^{\circ} \mathrm{C}$ for 30 minutes at 10,400 x g. Supernatant containing protein extract was frozen at $-80^{\circ} \mathrm{C}$.

Protein extracts were precipitated with a $10 \%$ TCA/acetone solution for 12 hours at $20^{\circ} \mathrm{C}$. Samples were rinsed with $100 \%$ acetone and allowed to dry before rehydration by working rehydration buffer (7M urea, 2M thiourea, 2\% CHAPS, 2\% Nonidet P-40, $0.002 \%$ bromophenol blue, $0.05 \%$ immobilized $\mathrm{pH}$ gradient (IPG) buffer and $100 \mathrm{mM}$ DTE). Rehydration occurred over a 12 hour period at $4{ }^{\circ} \mathrm{C}$. Impurities were removed through centrifugation and rehydrated protein extracts were stored at $-80^{\circ} \mathrm{C}$.

Protein concentrations were quantified using the 2D-Quant kit (GE Healthcare, Uppsala, Sweden). 


\subsubsection{Two-Dimensional Gel Electrophoresis (2D)}

An $11 \mathrm{~cm}$ IPG strip (pH 3-10) was used to separate 200ug of protein from each sample through isoelectric focusing (Bio-Rad, Hercules, CA). IPG strips were actively rehydrated for 12 hours and separated by isoelectric focusing using the Bio-Rad Protean IEF cell preset $11 \mathrm{~cm}$ rapid program (250V for $15 \mathrm{~min}, 8000 \mathrm{~V}$ for 2.5 hours and 35000 vhours).

Proteins were separated in the second dimention, by molecular weight, on precast Criterion $10 \%$ tris- $\mathrm{HCl} 11 \mathrm{~cm}$ gels using a Criterion Dodeca Cell (Bio-Rad, Hercules, CA) for 1 hour at 200V. All gels were run in duplicate.

Proteins were stained overnight with colloidal Coomassie Blue G-250 (Coomassie Blue G-250, $\mathrm{H}_{2} \mathrm{SO}_{4}, \mathrm{NaOH}$, glacial acetic acid and sterile water) and rinsed periodically with sterile water until protein spots were clearly visible. Stained gels were scanned and analyzed by Delta 2D gel image analysis software (DECODON, Germany). Spot volumes were analyzed using a t-test based on a null distribution that was generated using 1000 permutations to account for unequal variance and non-normal distribution of the data. Differences were considered significant at $\mathrm{P}<0.01$. 


\subsubsection{Tryptic Digestion and MALDI TOF/TOF Mass Spectrometry}

Protein spots were manually excised from $2 \mathrm{D}$ gels with a $1.5 \mathrm{~mm}$ tissue arrayer puncher (Beecher Instruments, Sun Prairie, WI) and stored at $-80^{\circ} \mathrm{C}$ in $0.5 \mathrm{ml}$ microfuge tubes.

Coomassie blue was removed from the gel plugs by two 30-minute incubations on a shaking plate with destaining buffer $\left(25 \mathrm{mM} \mathrm{NH} \mathrm{NH}_{4} \mathrm{HCO}_{3}\right.$ and $50 \%$ acetonitrile). Destaining was followed by a wash with $100 \%$ acetonitrile and an overnight incubation at $37^{\circ} \mathrm{C}$ in trypsin digestion solution (1ug/ul mass spectrometry grade porcine trypsin gold (Promega, Madison, WI) in $40 \mathrm{mM} \mathrm{NH}_{4} \mathrm{HCO}_{3}$ and $10 \%$ acetonitrile). Digested peptides were eluted from gel plugs through two 30-minute incubations on a shaking plate with analyte solution (0.1\% TFA and $33 \%$ acetonitrile). Supernatants were moved to new, $0.5 \mathrm{ml}$ collection tubes after each incubation. Eluted peptides from each sample were dehydrated in a $45^{\circ} \mathrm{C}$ speedvac centrifuge for 50 minutes and rehydrated in a matrix solution $(0.2 \mathrm{mg} / \mathrm{ml} \alpha$-cyano-4-hydrocinnamic acid (HCCA) in acetonitrile). Each peptide sample was plated individually on an anchorchip target (Bruker Daltonics, Billerica, MA), washed with a rinse buffer ( $0.1 \%$ TFA in $10 \mathrm{mM}$ ammonium phosphate) and recrystallized with a solution of ethanol, acetone, and 0.1\% TFA (6:3:1). Each sample was analyzed by ultraflex II MALDI-TOF/TOF mass spectrometry (Bruker Daltonics, Billerica, MA) and peptide mass fingerprints (PMF) were acquired and externally calibrated with FlexControl software (Bruker Daltonics, Billerica, MA). PMFs were further analyzed using MASCOT server launched from BioTools software (Bruker Daltonics, Billerica, MA) against the NCBI database. Carbamidomethylation and 
oxidation were set as fixed modifications for MASCOT searches with a maximum of one missed cleavage. PMF were further analyzed using MS/MS spectra using five to ten of the largest peaks per sample (excluding keratin and trypsin). Spectra were internally calibrated and processed using FlexAnalysis software (Bruker Daltonics, Billerica, MA). PMF and MS/MS spectra were combined and queried as described for PMF spectra analysis using the MS/MS spectra. 


\subsubsection{Protein Analysis}

Estimated molecular weight and isoelectric point $(\mathrm{pI})$ were calculated using ExPASy Bioinformatics Resource Portal software (www.expasy.org) and cellular localization, gene names and functions of proteins were acquired from the "UniProtKB" UniProt Protein Knowledgbase (UniProt Consortium, 2012) unless otherwise noted. 


\subsection{Results}

Through the use of Delta 2D, 223 individual protein spots were identified on the composite image of all gels. Of those 223,82 spots (37\%) differed in abundance between the two treatment groups ( $p<0.01$; see figure 3 ). Sixty-three spots were successfully matched to NCBI Blast database sequences and identified as listed in table 1. Of the 63 proteins, 30 increased in abundance, or showed an up-regulation in the differentiated cells and 33 decreased in abundance, or were down regulated in the differentiated cells.

In general the proteins identified to increase after differentiation were functionally related to cytoskeletal structure and dynamics, fatty acid synthesis, amino acid synthesis, protein synthesis and glycolysis. Down regulated proteins were generally related to calcium storage by the endoplasmic reticulum, mRNA processing in the nucleus, and the TCA cycle within the mitochondria.

Table 1 represents differentially expressed proteins between proliferating (undifferentiated) MAC-T cells and differentiated MAC-T under DIP lactation media conditions for 7 days. Identified proteins range in molecular weight from approximately 29 to $130 \mathrm{kDa}$, and in $\mathrm{pI}$ from 4 to 9 . Proteins within the table are grouped based on functional category and sorted within the group by protein name, direction of regulation and fold change. Repetitions in protein names are associated with separate spots, which may be explained by post-translational modifications or other differences that lead the same protein to have either a different mass or $\mathrm{pI}$. 
Figure 3. Fused Gel Image of MAC-T Protein Spots

Protein samples from proliferating and differentiated MAC-T cells were separated by isoelectric point (horizontal axis) and molecular weight (vertical axis). Image represents a fusion of all 12 gels ( $n=3$ per treatment, in duplicate). Spots that differed in abundance between treatments are circled and numbered. Numbers correspond with "Spot ID" in table 1 .

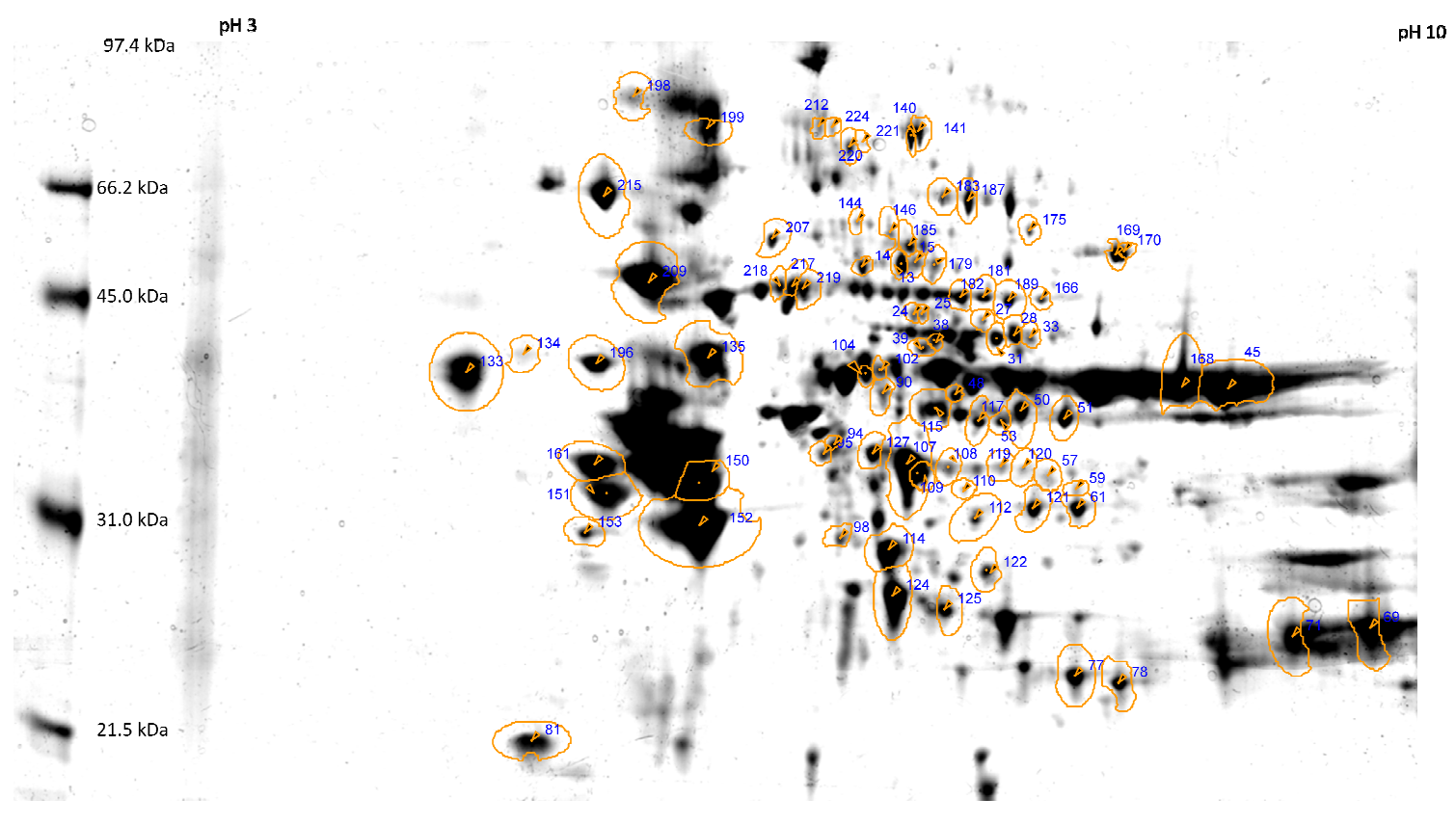


Figure 4. Heat Map of Significant MAC-T Proteins

Hierarchal clustering using Pearson's correlation of MAC-T protein spots that changed significantly between pregnancy and lactation states. Blue represents abundances lower than the average for that particular spot, while orange represents greater than average protein abundance. The columns represent individual gels clustered by treatment/cell state. Rows represent individual protein spots.

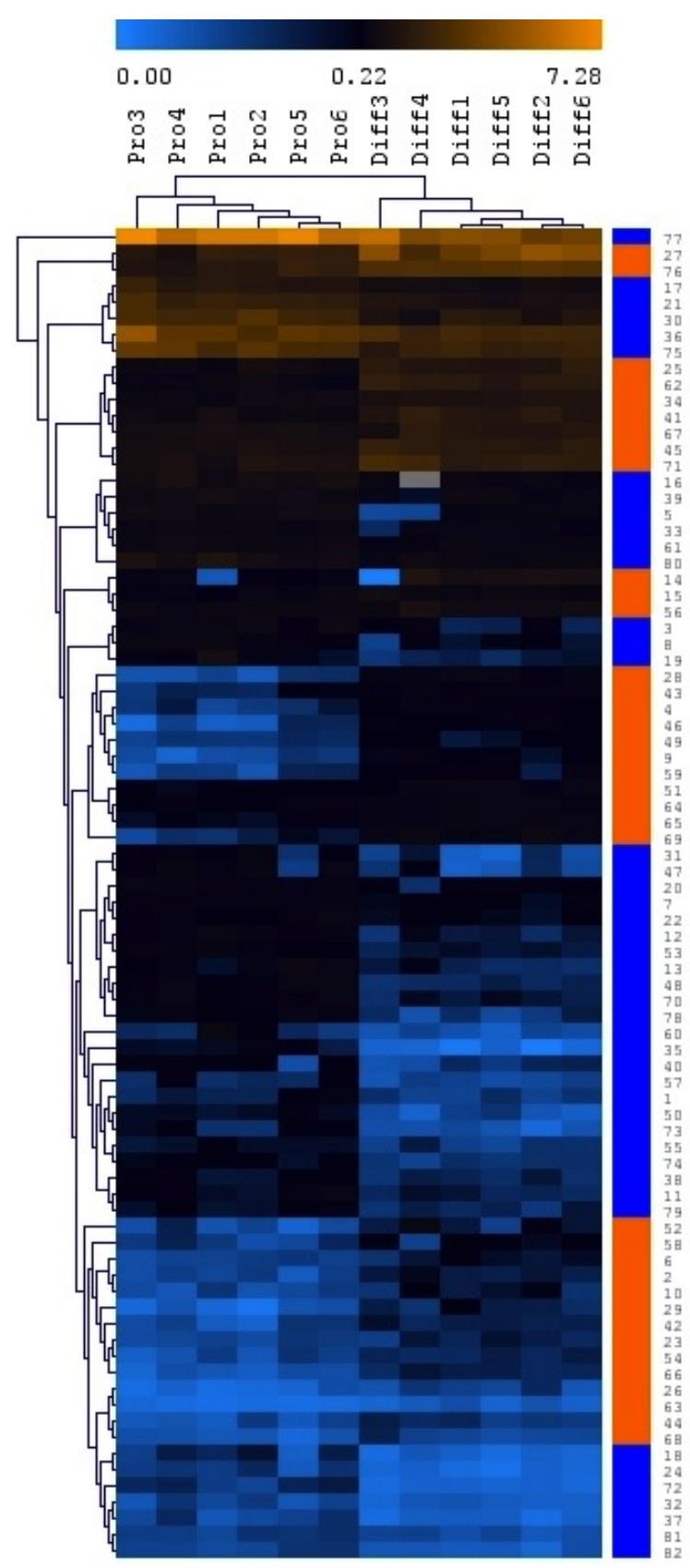


Table 1. Identified proteins that differed in abundance between proliferating and differentiated MAC-T cells. "Regulation Direction" refers to change in protein spot abundance from proliferating to differentiated cell state, which is quantified by "Fold Change". Fold change was calculated by dividing the mean spot abundance from differentiated cell gels by the mean abundance of the same spot from proliferating cell gels.

\begin{tabular}{rllrrrrr}
$\begin{array}{c}\text { Spot } \\
\text { ID }\end{array}$ & \multicolumn{1}{c}{ Protein Name } & $\begin{array}{l}\text { Gene } \\
\text { Name }\end{array}$ & $\begin{array}{c}\text { Regulation } \\
\text { Direction }\end{array}$ & $\begin{array}{c}\text { Fold } \\
\text { Change }\end{array}$ & $\begin{array}{c}\text { MW } \\
\text { P-value }\end{array}$ & $\begin{array}{c}\text { (kDa) } \\
\text { Predicted }\end{array}$ & $\begin{array}{c}\text { pI } \\
\text { Predicted }\end{array}$ \\
\hline \multicolumn{7}{c}{ Cytoskeletal Microfilaments } \\
\hline 152 & Actin, Beta & Actb & down & 0.69 & 0.003 & 41679.72 & 5.29 \\
151 & Keratin 13-like & Krt13 & up & 3.62 & $<0.001$ & 47183.24 & 4.86 \\
45 & Keratin 6A & Krt6A & up & 2.28 & $<0.001$ & 60782.58 & 8.28 \\
102 & Keratin, (type II) Cytoskeletal & Krt5 & down & 0.58 & 0.001 & 62449.11 & 6.90
\end{tabular}

\begin{tabular}{rllcrrrr}
\multicolumn{7}{c}{ Cytoskeletal Dynamics } \\
\hline 220 & (Predicted) Vinculin Isoform & Vin2 & up & 1.97 & 0.001 & 116642.35 & 5.83 \\
& 2 & & & & & & \\
13 & Ezrin & Ezr & up & 1.87 & $<0.001$ & 68717.49 & 6.06 \\
207 & Gelsolin Isoform A & Gsna & up & 2.93 & 0.003 & 85634.23 & 5.86 \\
125 & LIM and SH3 Domain Protein & Lasp1 & up & 1.57 & 0.002 & 29658.13 & 6.61 \\
& 1 & & & & & & \\
114 & Macrophage Capping Protein & Capg & up & 1.93 & $<0.001$ & 38851.79 & 6.17 \\
98 & Macrophage Capping Protein & Capg & up & 1.60 & 0.001 & 38851.79 & 6.17 \\
24 & Tripartite Motif-containing 29 & Trim29 & down & 0.72 & 0.004 & 64931.20 & 6.70
\end{tabular}

Calcium Trafficking/Storage

\begin{tabular}{lllrrrrr}
\hline 124 & Annexin A1 & Anxa1 & up & 1.76 & $<0.001$ & 38927.26 & 6.37 \\
209 & BiP (78kD Glucose-Regulated & Grp78 & down & 0.72 & $<0.001$ & 62978.81 & 5.31 \\
& Protein) & Calr & down & 0.54 & 0.001 & 48067.88 & 4.33 \\
133 & Calreticulin & Hsp90B1 & down & 0.53 & $<0.001$ & 92369.23 & 4.76 \\
215 & Endoplasmin Precursor & P4hb & down & 0.55 & $<0.001$ & 57167.77 & 4.80 \\
196 & Protein disulfide isomerase & Pdia3 & down & 0.55 & 0.001 & 56893.91 & 6.38 \\
104 & Protein Disulfide-isomerase & & & & & &
\end{tabular}

Nuclear Proteins

\begin{tabular}{|c|c|c|c|c|c|c|c|}
\hline 198 & $\begin{array}{l}\text { Heterogeneous Nuclear } \\
\text { Ribonucleoprotein U-like } \\
\text { Protein } 2\end{array}$ & Hnrnpul2 & down & 0.50 & $<0.001$ & 85139.05 & 4.84 \\
\hline 122 & Poly(rC)- Binding Protein 2 & Pcbp2 & up & 2.21 & $<0.001$ & 36777.74 & 6.60 \\
\hline 90 & $\begin{array}{l}\text { Pre-mRNA-processing Factor } \\
19\end{array}$ & Prpf19 & down & 0.47 & $<0.001$ & 55160.36 & 6.14 \\
\hline 31 & Prelamin-A/C & Lmna & down & 0.38 & 0.001 & 65082.57 & 6.54 \\
\hline 181 & Prelamin-A/C & Lmna & down & 0.58 & 0.001 & 65082.57 & 6.54 \\
\hline 182 & Prelamin-A/C & Lmna & down & 0.70 & 0.001 & 65082.57 & 6.54 \\
\hline \multicolumn{8}{|c|}{ Pentose Phosphate Pathway } \\
\hline 119 & $\begin{array}{l}\text { 6-Phosphogluconate } \\
\text { Dehydrogenase, } \\
\text { Decarboxylating }\end{array}$ & Pgd & up & 3.45 & 0.001 & 53042.87 & 6.65 \\
\hline \multicolumn{8}{|c|}{ Protein Synthesis } \\
\hline 187 & Elongation Factor 2 & Eef2 & up & 4.23 & $<0.001$ & 95306.96 & 6.41 \\
\hline
\end{tabular}




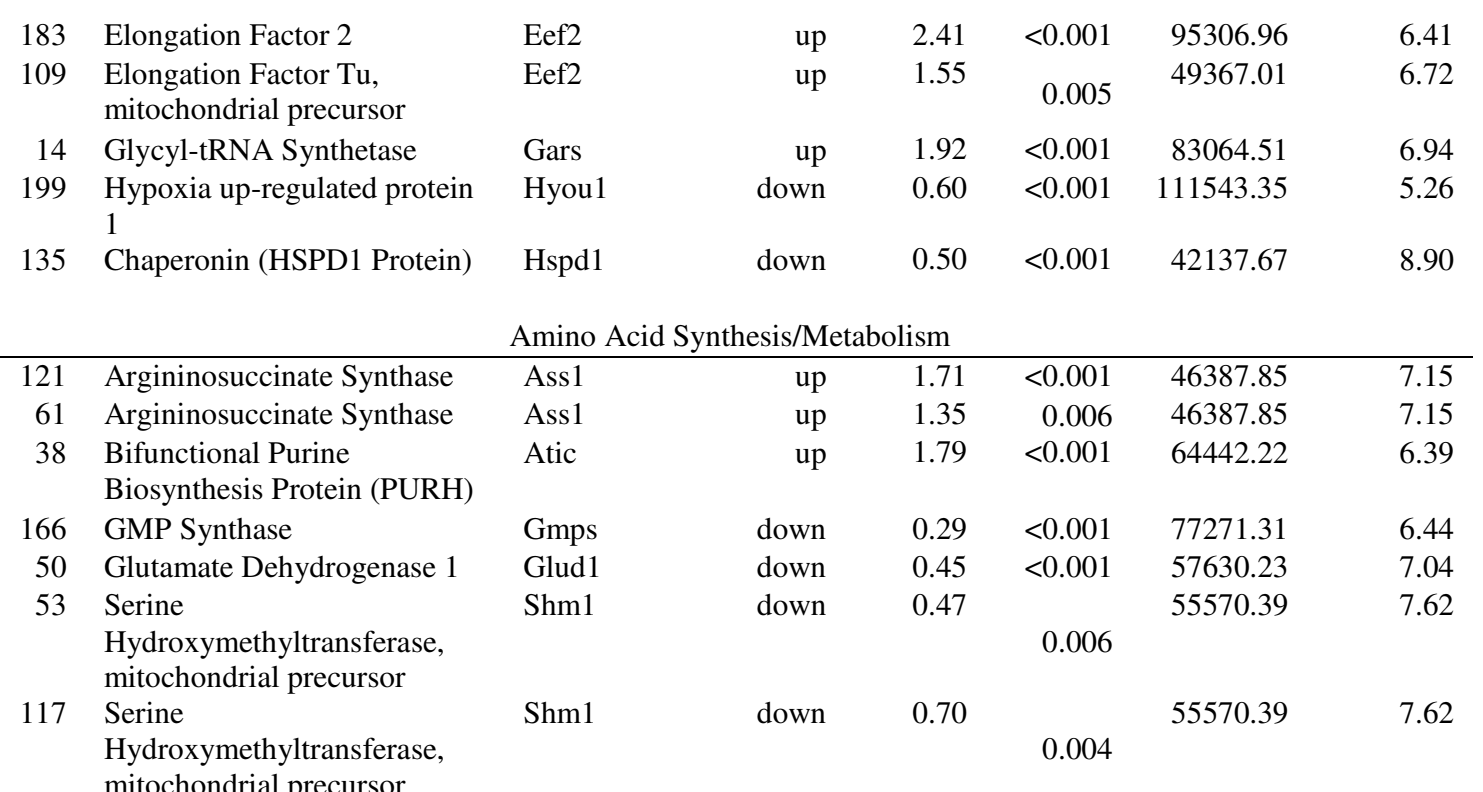

Glycolysis

\begin{tabular}{rlllllll}
\hline 127 & Alpha-Enolase & Eno1 & up & 3.26 & $<0.001$ & 47254.35 & 6.37 \\
108 & Alpha-Enolase & Eno1 & up & 3.25 & $<0.001$ & 47254.35 & 6.37 \\
95 & Alpha-Enolase & Eno1 & up & 2.06 & $<0.001$ & 47254.35 & 6.37 \\
107 & Alpha-Enolase & Eno1 & up & 1.91 & $<0.001$ & 47254.35 & 6.37 \\
71 & $\begin{array}{l}\text { Glyceraldehyde-3-Phosphate } \\
\text { Dehydrogenase }\end{array}$ & Gapdh & up & 2.36 & 0.001 & 35845.30 & 8.51 \\
69 & Glyceraldehyde-3-Phosphate & Gapdh & up & 1.51 & & & \\
& Dehydrogenase & Pgm1 & up & 3.04 & 0.001 & 61550.75 & 6.36
\end{tabular}

TCA Cycle/Mitochondrial Energy Metabolism

\begin{tabular}{|c|c|c|c|c|c|c|c|}
\hline 48 & $\begin{array}{l}\text { Dihydrolipoyl } \\
\text { Dehydrogenase, } \\
\text { mitochondrial }\end{array}$ & Dld & down & 0.52 & 0.001 & 54153.06 & 7.59 \\
\hline 169 & Mitochondrial Aconitase 2 & Aco 2 & down & 0.60 & 0.002 & 78501.72 & 6.67 \\
\hline 28 & $\begin{array}{l}\text { Phosphoenolpyruvate } \\
\text { Carboxykinase (GTP), } \\
\text { mitochondrial }\end{array}$ & Pck1 & down & 0.52 & $<0.001$ & 70604.72 & 8.14 \\
\hline 179 & $\begin{array}{l}\text { Phosphoenolpyruvate } \\
\text { Carboxykinase (GTP), } \\
\text { mitochondrial }\end{array}$ & Pck1 & down & 0.62 & $<0.001$ & 70604.72 & 8.14 \\
\hline 115 & $\begin{array}{l}\text { Phosphoglycerate } \\
\text { Dehydrogenase }\end{array}$ & Phgdh & up & 1.51 & 0.004 & 56315.10 & 6.71 \\
\hline 140 & Pyruvate Carboxylase & $\mathrm{Pc}$ & down & 0.13 & $<0.001$ & 129728.71 & 6.32 \\
\hline 141 & Pyruvate Carboxylase & $\mathrm{Pc}$ & down & 0.38 & $<0.001$ & 129728.71 & 6.32 \\
\hline 168 & Pyruvate Kinase Isozyme M2 & $\mathrm{Pkm} 2$ & up & 1.81 & $<0.001$ & 61388.73 & 8.62 \\
\hline 25 & $\begin{array}{l}\text { Succinate Dehydrogenase } \\
\text { (complex subunit A) }\end{array}$ & Sdha & down & 0.57 & $<0.001$ & 60804.94 & 6.19 \\
\hline \multicolumn{8}{|c|}{ Cell Signaling } \\
\hline 51 & $\begin{array}{l}\text { Adenylate cylase-assosiated } \\
\text { protein } 1\end{array}$ & Cap1 & down & 0.72 & 0.004 & 51169.38 & 7.16 \\
\hline 78 & $\begin{array}{l}\text { Guanine nucleotide-binding } \\
\text { protein subunit beta-2-like } 1\end{array}$ & Gnb211 & down & 0.66 & 0.001 & 35068.57 & 7.60 \\
\hline 185 & Phosphlipase C-delta 1 & Plcd1 & up & 1.80 & $<0.001$ & 86019.27 & 6.27 \\
\hline 81 & YWHAZ Protein (Homo & YWHAZ & up & 3.43 & 0.009 & 35313.77 & 6.97 \\
\hline
\end{tabular}


sapien)

\begin{tabular}{|c|c|c|c|c|c|c|c|}
\hline \multicolumn{8}{|c|}{ GTP Synthesis } \\
\hline 94 & $\begin{array}{l}\text { Rab GDP Dissociation } \\
\text { Inhibitor Beta }\end{array}$ & Gdi2 & up & 1.74 & 0.002 & 50455.67 & 5.93 \\
\hline \multicolumn{8}{|c|}{ Cell Surface/Membrane Proteins } \\
\hline 224 & (Predicted) Integrin Alpha-3 & Itga3 & down & 0.33 & $<0.001$ & 95515.79 & 6.35 \\
\hline 153 & 40S Ribosomal Protein SA & Rpsa & down & 0.40 & 0.001 & 32876.44 & 4.80 \\
\hline 77 & $\begin{array}{l}\text { Voltage-Dependent Anion- } \\
\text { Selective Channel Protein } 2\end{array}$ & Vdac2 & down & 0.49 & 0.001 & 31599.56 & 7.47 \\
\hline \multicolumn{8}{|c|}{ Serum Protein } \\
\hline 218 & Albumin (ALB) & Alb & down & 0.34 & 0.003 & 69190.43 & 5.88 \\
\hline 217 & Albumin (ALB) & Alb & down & 0.35 & 0.002 & 69190.43 & 5.88 \\
\hline
\end{tabular}

* Molecular weight (MW) and pI values estimated by ExPASy - Bioinformatics Resource Portal (www.expasy.org) 


\subsection{Discussion}

This study was designed to compare global protein expression in MAC-T cells before and after in vitro differentiation. Our interest in this transition within the MAC-T cell line arose due to results from an earlier experiment, which compared the proteomes of MAC$\mathrm{T}$ cells that had been differentiated in vitro and treated with or without exogenous growth hormone. Many of the proteins observed to change with GH treatment have known functions that may be associated with the transition to differentiation or establishment of lactogenesis in the mammary gland. The intent in designing the current study was to compare the stages of proliferation and differentiated MAC-T cells in order to then compare these results with those from the GH study. This discussion will address the changes in the proteome we observed in the current study and assess similarities between the current study and the GH treatment experiment previously conducted by Johnson et al.

The majority of metabolic proteins that we observed to differ in abundance were related to the glycolytic pathway, TCA cycle and NADPH production, which is what we would expect from a bovine mammary epithelial cell preparing for lactose and fatty acid synthesis. We also observed changes in proteins related to cytoskeletal dynamics and RNA processing which was also expected due to the structural changes that must occur in order for lactation to proceed. 


\section{$\underline{\text { Calcium Storage/Trafficking Proteins }}$}

Specifically related to the endoplasmic reticulum (ER), we observed down-regulation of ER resident proteins: calreticulin, endoplasmin (precursor), BiP (precursor; also known as $78 \mathrm{kD}$ glucose regulated protein) and two forms of protein disulfide-isomerase (P4hb and Pdia3). Calcium, commonly associated with the health benefits of milk is also necessary for a number of functions throughout the cytoplasm of all cells. Calcium is stored in the ER and must be transported throughout the cell via "chaperones" in order to perform its functions. While all of the ER proteins we detected have calcium binding capabilities, calreticulin has the highest capacity and with a phosphorylation site for casein kinase II may have a role in the secretion of calcium in milk (Rowling, 1994).

The fact that we saw a decrease in abundance of these ER proteins after differentiation may illustrate a decreased need for the intracellular distribution of calcium for functional processes related to proliferation and perhaps a faster turnover between calcium influx and output through casein secretion. If this were the case, there may be a decrease in the need for ER storage and chaperoning of calcium by ER proteins. This hypothesis is supported by the up regulation of the protein annexin 1 . Annexin 1 binds phospholipid, of which the cell membrane is made, but only when also bound to calcium, leading to a possible connection between annexin 1 and the exocytosis of secretory vesicles containing milk components (Creutz, 1992). 


\section{$\underline{\text { Metabolic Proteins }}$}

In the ruminant mammary gland glucose availability is limited, and lactose synthesis is generally believed to be the first priority of glucose use. Consistent with this theory, we saw an up-regulation in phosphoglucomutase which is an enzyme involved in lactose synthesis. We also observed changes in other proteins related to glucose use including up-regulation of several glycolytic enzymes, including glyceraldehyde-3-phosphate dehydrogenase, alpha-enolase and phosphoglycerate dehydrogenase. The increase in abundance of these proteins indicates an increase in glucose breakdown to pyruvate, probably related to the increased energy demands during milk synthesis. However, the fate of the increased pyruvate stores that this pathway would generate is debatable.

Within the mitochondrial TCA cycle, we observed a down-regulation in both dihydrolipoyl dehydrogenase and pyruvate carboxylase which are the two mitochondrial catalysts for reactions in which pyruvate is a substrate. Phosphenolpyruvate carboxykinase (PEPCK), which is the enzyme that can reversibly convert oxaloacetate to phosphoenolpyruvate (PEP), was also down regulated. However, pyruvate kinase was up regulated and this is the enzyme completing the final and irreversible transition of PEP to pyruvate. The changes in the above metabolic proteins appear to indicate a build up of pyruvate though glycolysis and conversion of PEP to pyruvate as well as an inhibition of the TCA cycle. Under aerobic conditions, if the fate of pyruvate is not the production of ATP through the TCA cycle, it may be participating in a transamination reaction in the presence of glutamate to produce both alpha-ketoglutarate and alanine. Alanine is a nonessential amino acid (NEAA) that may be required to produce new proteins, and alpha- 
ketoglutarate can contribute to other pathways. For example, mitochondrial aconitase was down regulated, and this enzyme is responsible for another conversion within the TCA cycle involving the reversible transition of citrate to isocitrate. Alpha-ketoglutarate can also be converted to isocitrate in the mitochondria, and isocitrate can be shuttled out of the mitochondria to the cytosol and used as a precursor to NADPH production. If there is an abundance of isocitrate in the mitochondria as a result of transamination of pyruvate, it would reduce the need to convert citrate to isocitrate, sparing the energy that reaction would cost. NADPH is the required reducing agent for fatty acid synthesis, and the majority of it is most likely produced by this particular reaction in the ruminant due to absence of citrate lyase activity and limited availability of glucose for the pentose phosphate pathway. Even though it is most likely secondary to isocitrate dehydrogenase production, the pentose phosphate pathway remains a source of NADPH production, and this is supported by our data through the observed increase in abundance of 6phosphogluconate dehydrogenase (for reference, see figures 1 and 2 in chapter 1).

\section{Cytoskeletal Proteins and Cytoskeletal Dynamics-related Proteins}

As epithelial cells differentiate they change in structure, shape and motility and changes in cytoskeletal proteins related to these transformations were to be expected. The cellular cytoskeleton is made up of microfilaments assembled from actins, intermediate filaments and microtubules. Among cytoskeletal proteins detected to change, we saw an up regulation in keratins $6 \mathrm{a}$ and 13 , which are both typical intermediate filaments in epithelial cells. Specifically keratin 6a is expressed only in luminal epithelial cells and cells of terminal end buds within the mammary ductal system, a fact that supports our 
selection of MAC-T as a model for this cell type (Bu, 2011). Additionally, we observed a down regulation of keratin 5, and this is a filament expressed during the differentiation of epithelial cells and is perhaps no longer necessary to a fully differentiated, lactating phenotype.

Beta-actin was the only actin sub-unit in which we detected a change and it was down regulated. This does not necessarily contradict the up regulation of keratins because reorganization is bound to change demands for different building materials in the cytoskeleton. Specifically, actin is often associated with cell motility, an important characteristic for epithelial cells during proliferation in order to populate a mammary gland (Mayanagi, 2011). However, once the functional epithelium is established and differentiated to a lactating phenotype, motility is no longer necessary and would likely hinder milk secretion. Complementary to this analysis, we saw up regulation of proteins related to cytoskeletal dynamics and actin re-organization such as gelsolin-a, LIM and SH3 domain protein 1 and macrophage capping protein, which indicate a change in cell structure that may have altered the activity of actin post-translation. LIM and SH3 domain protein 1 has been identified in other secretory epithelial cell types as well, and is thought to be involved in linking intracellular signaling pathways, including, but not limited to, regulating actin-related ion transport (Chew, 2000).

Gelsolin is an actin-capping and severing protein, meaning it binds to actin filaments to prevent the exchange of monomers with the unique ability to both assemble or sever formed filaments. Gelsolin is decreased in breast tumors, and up-regulate in response to 
anti-growth medication indicating a preventative effect on motility and proliferation (Brackley, 2011). Macrophage capping protein is alternately known as "gelsolin-like capping protein" and shares many characteristics with gelsolin in relation to actin-based cell motility although it was originally isolated from alveolar macropahges (Zhu, 2011). Interestingly, macrophage capping protein was also up-regulated in response to $\mathrm{GH}$ treatment in the previously conducted MAC-T experiment.

In relation to cytoskeletal dynamics, we saw an increase in the abundance of proteins viniculin 2 and ezrin which both function as intermediates connecting the plasma membrane of the cell to the cytoskeleton. Viniculin binds actin filaments and is involved in cell-to-cell and cell matrix adhesion (Coll, 1995). Ezrin has been associated specifically with the apical membrane and the maintenance of polarity in epithelial cells. Adhesion for signaling and established polarity are essential characteristics for lactation in the epithelium (Saotome, 2004).

Lamin $\mathrm{A} / \mathrm{C}$ are also cytoskeletal proteins, but are more closely related to the nucleus. These intermediate filament proteins, present in all mammals, comprise the inner most layer of the nuclear membrane termed nuclear lamina. Recently, it has been proposed that lamins are not only structural in nature, but also interact with chromatin affecting gene regulation (Puckelwartz, 2011). Lamin-associated domains have been identified which allow chromatin to interact directly with the nuclear lamin, causing a change in transcription, which is most often a repressive effect (Puckelwartz, 2011). If differentiation does in fact reduce the abundance of nuclear lamins, and therefore reduces 
the interaction between lamins and repressive lamin-associated domains, this effect may contribute to a change in genes being transcribed for the new, functional cell state.

\section{Proteins of Particular Interest}

One unexpected change was observed in YWHAZ protein, one of the most significantly up-regulated proteins observed. YWHAZ is known to be involved in the regulation of a spectrum of general cell signaling pathways. Its increase of greater than 3 fold between states of differentiation is interesting due to the fact that the gene for this protein has been previously been deemed appropriate as a "housekeeper" or reference gene for PCR studies in 33 bovine tissues including the mammary gland (Lecchi, 2012). This provides an excellent example of discrepancy between mRNA and protein abundance. While it may be a good reference gene on the transcript level, the abundance of this protein may not be dictated by the abundance of mRNA.

Another unexpected result was the up-regulation of argininosuccinate synthase, which we observed in differentiated MAC-T. Argininosuccinate synthase is an enzyme generally associated with the urea cycle that is not typically associated with the mammary gland. In fact until very recently, this enzyme has been linked exclusively to the liver. In a review published in 2011, it was noted that argininosuccinate synthase plays a role not only in the urea cycle, but also in several other pathways including de novo arginine synthesis (Haines, 2011). Arginine is often considered a "semi-essential" amino acid, due to the fact that most adult animals produce enough arginine in the kidneys to balance dietary sources, reaching the required metabolic demand (Haines, 2011). In the neonate however, 
enterocytes also express argininosuccinate synthase perhaps due to the fact that milk is relatively low in arginine when compared to the needs of growing young. The uptake of arginine from the plasma by the lactating mammary gland of the sow has been demonstrated to be significantly lower than the output of arginine in milk, indicating a demand for arginine in the process of lactation (O'Quinn, 2002). It is feasible then, that de novo arginine synthesis is occurring within the lactating MEC in order to meet this demand. Specific fates of this amino acid warrant further investigation.

\section{$\underline{\text { Relationship with Growth Hormone Experiment }}$}

In the previously conducted study comparing differentiated MAC-T cells treated with and without GH, analysis suggested a possible parallel between the transition of differentiation and the direct effect of $\mathrm{GH}$ on the mammary epithelial cell. When comparing results from the two experiments, there is a great deal of overlap in the functional groups of proteins that changed in abundance, and several of the same proteins changed in the same direction of regulation. Notably, the up regulation observed in pathways promoting and increase in NADPH production are similar to those seen with GH treatment. As discussed, NADPH is an important factor in fatty acid synthesis, which is essential to milk production, especially in the ruminant. Also similar was the increase in glycolytic enzyme, alpha-enolase, which facilitates the last step in glycolysis resulting in the production of phosphoenolpyruvate from 2-phosphoglycerate. This increase may indicate an increase in the use of glycerol from TAG for the synthesis of pyruvate, which, as previously discussed, may be contributing to NEAA synthesis through transamination. By taking advantage of glycerol in this manner, glucose may be spared for lactose 
synthesis without detriment to the TCA cycle and associated pathways in the ruminant cell.

Additionally, there were similarities in the changes of cytoskeletal proteins indicating a similar re-organization of the cell structure due to functional differentiation of the cell and treatment with $\mathrm{GH}$. The hypothesis postulating an overlap between the effect of GH and the changes that occur between the proliferation of mammary epithelium and the stage of functional differentiation is supported in part by these similarities, providing additional evidence that the effect of $\mathrm{GH}$ on the mammary epithelium may be to potentiate the process of differentiation. Future experiments could be designed based on this hypothesis with more specificity to individual genes, proteins and pathways. A time course experiment would also be beneficial to observe how changes occur through the process of differentiation as opposed to just looking at singular time-points before and after this functional shift in the mammary epithelium.

As we have demonstrated, immortalized cell lines are excellent sources upon which hypotheses may be based. These cells are homogenous, easy to obtain and undergo structural and functional changes in vitro that qualify as induced differentiation. However, it is important to consider the probable effects of human intervention and the unnatural, in vitro environment. The following chapter will describe an experiment designed to compare what we observed in the MAC-T cell line with primary cells isolated before and after in vivo differentiation, in order to test and improve our hypotheses. 
CHAPTER 3 - A proteomic analysis of differentiation, in vivo through the comparison primary mammary epithelial cells from pregnant and lactating mice

\subsection{Introduction}

Although rudimentary development of the mammary gland begins during fetal development and puberty, a mammary gland does not fulfill its functional potential until the female has undergone a full-term pregnancy and parturition (Gjorevski, 2011). The mammary gland undergoes major development during pregnancy, characterized by the tertiary side-branching of the ductal structure and the exponential proliferation of epithelial cells, some of which will undergo a final differentiation to become secretory, milk-producing cells (Brisken, 2006). In the context of protein biosynthesis, this transition begins with the up-regulation of enzymes involved in the synthesis of milk components, specifically lactose, caseins, and whey proteins alpha-lactalbumin and betalactoglobulin. Although the hormonal signals prompting this switch in cellular function of the mammary epithelium have long been understood, the molecular events within the epithelial cell, which physically establish the new phenotype, are still somewhat unclear (Gjorevski, 2011).

In this study, primary mammary epithelial cells (pMEC) were isolated from whole mammary glands of ICR mice at mid-pregnancy or peak lactation. Total protein was extracted from each cell type and global protein expression was visualized by twodimensional gel electrophoresis (2DE) before identification of individual proteins that 
changed significantly in abundance through MALDI-TOF/TOF mass spectrometry for analysis. 
3.2 Methods

All reagents were purchased from Sigma Aldrich (St. Louis, MO) unless otherwise noted. 


\subsubsection{Animals}

ICR mice were purchased from Taconic Farms, Inc. (Oxnard, CA). All protocols were designed in accordance with the PHS Policy for Humane Care and use of Laboratory Animals and approved by the California Polytechnic State University Institutional Animal Care and Use Committee. 


\subsubsection{Primary Cell Isolation}

Fat pads were excised from 7-10 week-old ICR outbred mice at either day 10 of pregnancy or day 10 of lactation and rinsed in 1X Hank's Balanced Salt Solution (HBSS). Tissue was manually minced to fragments of approximately $3 \mathrm{~mm}^{3}$ and digested in a collagenase, trypsin, EDTA and Dulbecco's Modified Eagle's Medium (DMEM) cocktail during a $90-$ minute shaking incubation at $37^{\circ} \mathrm{C}$. The cell pellet was sequentially re-suspended and incubated in red blood cell (RBC) lysis buffer (Millipore, MA), EDTA and DNase solutions before filtration through a 100um filter. As fibroblasts (a contaminating cell type) adhere very quickly to plastic, they were removed through a one-hour incubation on a T-182 flask. Epithelial cells that remained in suspension after

one hour were removed, centrifuged and re-suspended in a 1x DMSO cell freezing medium and brought to $-80^{\circ} \mathrm{C}$ over night. Frozen vials were stored in liquid nitrogen until the date of protein extraction. 
3.2.3 Protein Isolation, 2DE, Tryptic Digestion and MALDI TOF/TOF Mass Spectrometry and Data Analysis

All protein samples were isolated, treated and analyzed as described in chapter 2 , sections 2.2.2-2.2.5. 


\subsubsection{Flow Cytometry}

Viability of primary cells was determined through the use of ViaCount (Guava/Millipore) and its associated computer application in conjunction with a Millipore flow cytometer. Cell pellets from each vial were collected by centrifugation at $400 \mathrm{x}$ g for 5 minutes. Cell freezing media was removed and pellets were rinsed in phosphate buffered saline solution (PBS) twice. Two aliquots of each cell type were taken at this point for cell viability estimation. Trypan blue (Thermo Scientific, South Logan, UT) was added to the first aliquot of each cell type for visual examination of viability on a hemocytometer (Hausser Scientific, Horsham, PA). This visual estimation was compared with flow cytometry after the second aliquot was incubated with ViaCount solution according to the product literature and suggested protocols. 


\subsection{Results}

Flow cytometry determined cells isolated from pregnant mice to be $40 \%$ viable and cells from lactating mice to be $41 \%$ viable immediately after thaw from liquid nitrogen. Unfortunately, our efforts to validate the epithelial origin of the primary cells were inconclusive (please see appendix).

Through the use of Delta2D, 125 spots on the composite image of all gels were identified to be significantly different between the two treatment groups $(\mathrm{p}<0.01)$. A total of 92 spots were successfully matched to NCBI Blast database sequences to be identified as specific proteins listed in table 2 . Of the 92 proteins identified to change, 45 proteins were up regulated and 47 were down regulated in mammary epithelial cells from lactating mice compared to pregnant. Overall, 18 proteins matched proteins listed in table 1 in the previous chapter, although the direction of regulation was the same for only 7 of those 18; the remaining similar proteins were regulated in the opposite direction. Although this overlap in specific proteins may seem insubstantial, the functional groups into which changing proteins were divided show great similarity.

In general, the proteins that increased in abundance from pregnancy to lactation were functionally related to fatty acid synthesis, amino acid catabolism, tricarboxylic acid cycle and electron transport chain, and secreted proteins. The down-regulated proteins were generally related to cytoskeletal structure and dynamics, protein synthesis, mRNA processing and transcription, and molecular chaperoning. 
Table 2 represents differentially expressed proteins between proliferating cells isolated from the developing mammary gland of a mid-pregnant ICR mouse and differentiated cells isolated from a lactating ICR mouse. Identified proteins range in molecular weight from approximately 23 to $272 \mathrm{kDa}$, and in $\mathrm{pI}$ from 4 to 11 . Proteins within the table are grouped based on functional category and sorted within the group by protein name, direction of regulation and fold change. Repetitions in protein names are associated with separate spots, which may be explained by post-translational modifications or other differences that lead the same protein to have either a different mass or pI. 
Figure 5. Fused Gel Image of Primary Murine Mammary Epithelial Cell Protein Spots

Protein samples from the mammary epithelial cells isolated from pregnant and lactating mice were separated by isoelectric point (horizontal axis) and molecular weight (vertical axis). Image represents a fusion of all 12 gels ( $n=3$ per treatment, in duplicate). Spots that differed in abundance between treatments are numbered. Numbers correspond with "Spot ID" in table 2.

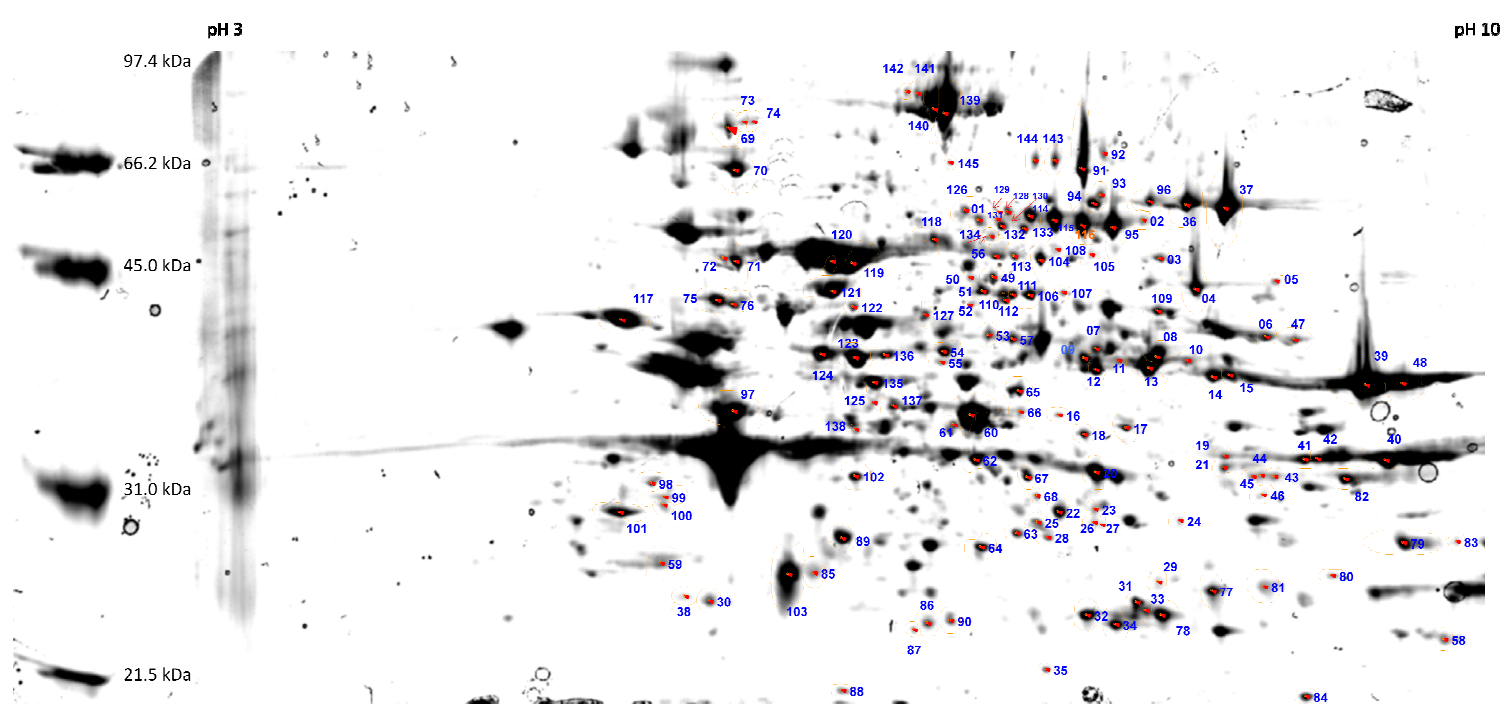




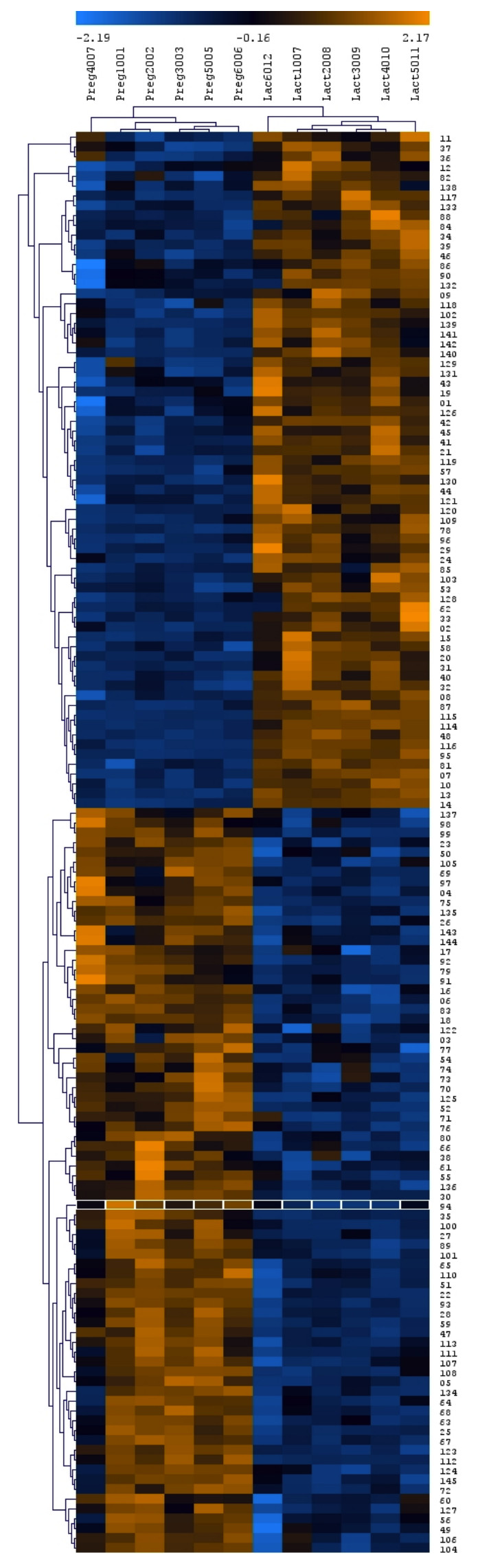

Figure 6. Heat Map of Significant Primary Murine Mammary Epithelial Cell Proteins

Hierarchal clustering using Pearson's correlation of murine mammary epithelial cell protein spots that changed significantly between pregnancy and lactation states. Blue represents abundances lower than the average for that particular spot, while orange represents greater than average protein abundance. The columns represent individual gels clustered by treatment/cell state. Rows represent individual protein spots. 
Table 2. Identified proteins that differed in abundance between mammary epithelial cells isolated from pregnant and lactating mice. "Regulation Direction" refers to the change in protein spot abundance from pregnant to lactating cell stages, which is quantified by "Fold Change". Fold change was calculated by dividing the mean spot abundance from lactating mouse gels by the mean abundance of the same spot from pregnant mouse gels.

\begin{tabular}{|c|c|c|c|c|c|c|c|}
\hline $\begin{array}{l}\text { Spot } \\
\text { ID }\end{array}$ & Protein Name & $\begin{array}{l}\text { Gene } \\
\text { Name } \\
\end{array}$ & $\begin{array}{c}\text { Regulation } \\
\text { Direction } \\
\end{array}$ & $\begin{array}{c}\text { Fold } \\
\text { Change } \\
\end{array}$ & $\begin{array}{r}\text { P- } \\
\text { value }\end{array}$ & $\begin{array}{l}\text { MW (Da) } \\
\text { Predicted } \\
\end{array}$ & $\begin{array}{c}\text { pI } \\
\text { Predicted }\end{array}$ \\
\hline \multicolumn{8}{|c|}{ Cytoskeletal Microfilaments } \\
\hline 97 & Keratin 18 & Krt18 & down & 0.41 & 0.003 & 47460.24 & 5.3 \\
\hline 57 & Keratin 5 & Krt5 & up & 2.34 & $<0.001$ & 61742.60 & 7.6 \\
\hline 136 & Keratin 8 & Krt8 & down & 0.34 & $<0.001$ & 54531.46 & 5.7 \\
\hline 123 & Keratin 8 & Krt8 & down & 0.45 & 0.002 & 54513.50 & 5.7 \\
\hline 124 & Keratin 8 & Krt8 & down & 0.53 & 0.006 & 54531.46 & 5.7 \\
\hline 72 & Vimentin & Vim & down & 0.40 & 0.003 & 51533.09 & 5.0 \\
\hline \multicolumn{8}{|c|}{ Cytoskeletal Dynamics } \\
\hline 64 & Elfin & Pdlim1 & down & 0.29 & 0.006 & 35751.89 & 6.4 \\
\hline 63 & $\begin{array}{l}\text { LIM and SH3 Domain } \\
\text { Protein } 1\end{array}$ & LASP1 & down & 0.29 & 0.003 & 29975.31 & 6.6 \\
\hline 67 & $\begin{array}{l}\text { Macrophage Capping } \\
\text { Protein, isoform } 2\end{array}$ & CAPG & down & 0.25 & 0.002 & 38744.68 & 6.5 \\
\hline 117 & $\begin{array}{l}\text { Protein Disulfide-Isomerase } \\
\text { (precursor) }\end{array}$ & P4hb & up & 2.80 & $<0.001$ & 57022.77 & 4.8 \\
\hline
\end{tabular}

\begin{tabular}{|c|c|c|c|c|c|c|c|}
\hline \multicolumn{8}{|c|}{ NADPH Production } \\
\hline 18 & $\begin{array}{l}\text { Isocitrate Dehydrogenase, } \\
\text { cytoplasmic }\end{array}$ & Idh1 & down & 0.40 & 0.002 & 46644.47 & 6.7 \\
\hline 81 & $\begin{array}{l}\text { Pyrroline-5-carboxylate } \\
\text { reductase } 2\end{array}$ & Pycr2 & up & 1.95 & 0.002 & 33637.62 & 7.7 \\
\hline 4 & Transketolase & Tkt & down & 0.54 & 0.001 & 67587.58 & 7.2 \\
\hline \multicolumn{8}{|c|}{ Fatty Acid Synthesis } \\
\hline 21 & $\begin{array}{l}\text { Acyl-coenzyme A } \\
\text { Dehydrogenase, medium } \\
\text { chain }\end{array}$ & Acadm & up & 2.01 & $<0.001$ & 46407.57 & 8.6 \\
\hline 87 & Fatty Acid Synthase & Fasn & up & 5.46 & $<0.001$ & 272256.77 & 6.1 \\
\hline 33 & $\begin{array}{l}\text { Monoglyceride Lipase } \\
\text { (isoform a) }\end{array}$ & Mgll & up & 3.45 & $<0.001$ & 35233.96 & 7.2 \\
\hline
\end{tabular}

\begin{tabular}{rllcrrrr}
\multicolumn{7}{c}{ Protein Synthesis } \\
\hline 144 & Elongation Factor 2 & Eef2 & down & 0.46 & 0.005 & 95252.89 & 6.4 \\
143 & Elongation Factor 2 & Eef2 & down & 0.50 & 0.009 & 95252.89 & 6.4 \\
91 & Elongation Factor 2 & Eef2 & down & 0.58 & $<0.001$ & 95252.89 & 6.4 \\
127 & Serine, tRNA ligase & Sars & down & 0.43 & $<0.001$ & 58720.97 & 6.2
\end{tabular}

\begin{tabular}{|c|c|c|c|c|c|c|c|}
\hline \multicolumn{8}{|c|}{ Amino Acid Metabolism } \\
\hline 111 & $\begin{array}{l}\text { Bifunctional Purine } \\
\text { Biosynthesis Protein } \\
\text { (PURH) }\end{array}$ & Atic & down & 0.33 & $<0.001$ & 64177.42 & 6.5 \\
\hline 7 & $\begin{array}{l}\text { Inosine-5'-monophosphate } \\
\text { Dehydrogenase } 2\end{array}$ & Impdh2 & up & 1.87 & $<0.001$ & 55779.77 & 6.3 \\
\hline 65 & $\begin{array}{l}\text { Serine } \\
\text { Hydroxymethyltransferase }\end{array}$ & Shmt2 & down & 0.36 & $<0.001$ & 52551.50 & 6.5 \\
\hline
\end{tabular}




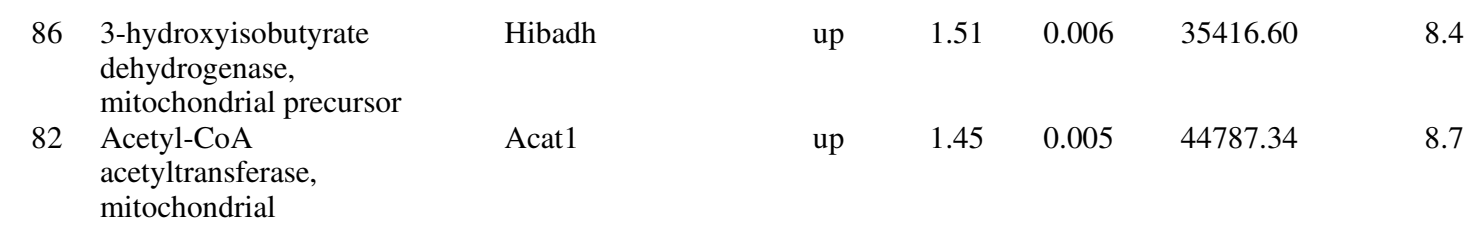

Glycolysis

\begin{tabular}{|c|c|c|c|c|c|c|c|}
\hline 60 & Alpha-Enolase & Eno1 & down & 0.58 & 0.004 & 47098.24 & 6.2 \\
\hline \multicolumn{8}{|c|}{ Mitchondrial Matrix/TCA Cycle } \\
\hline 96 & Aconitase 2 , mitochondrial & Aco 2 & up & 2.30 & $<0.001$ & 85444.00 & 8.1 \\
\hline 36 & Aconitase 2 , mitochondrial & Aco 2 & up & 1.59 & 0.01 & 85444.00 & 8.1 \\
\hline 37 & Aconitase 2 , mitochondrial & Aco 2 & up & 1.42 & 0.002 & 85444.00 & 8.1 \\
\hline 8 & Aldehyde Dehydrogenase & Aldh2 & up & 2.02 & 0.002 & 57924.49 & 8.3 \\
\hline 109 & Aldehyde Dehydrogenase & Aldh4a1 & up & 2.02 & $<0.001$ & 39448.25 & 7.8 \\
\hline 145 & $\begin{array}{l}\text { Alpha-ketoglutarate } \\
\text { Dehydrogenase }\end{array}$ & Ogdh & down & 0.30 & 0.005 & 117683.21 & 6.5 \\
\hline 41 & $\begin{array}{l}\text { Citrate Synthase, } \\
\text { mitochondrial precursor }\end{array}$ & $\mathrm{CS}$ & up & 6.13 & $<0.001$ & 51703.38 & 8.7 \\
\hline 42 & $\begin{array}{l}\text { Citrate Synthase, } \\
\text { mitochondrial precursor }\end{array}$ & Cs & up & 3.48 & $<0.001$ & 51703.38 & 8.7 \\
\hline 40 & $\begin{array}{l}\text { Citrate Synthase, } \\
\text { mitochondrial precursor }\end{array}$ & Cs & up & 2.37 & 0.001 & 51703.38 & 8.7 \\
\hline 19 & $\begin{array}{l}\text { Citrate Synthase, } \\
\text { mitochondrial precursor }\end{array}$ & Cs & up & 1.84 & $<0.001$ & 51703.38 & 8.7 \\
\hline 12 & $\begin{array}{l}\text { Glutamate Dehydrogenase } 1 \text {, } \\
\text { mitochondrial }\end{array}$ & Glud1 & up & 1.43 & 0.004 & 61298.17 & 8.1 \\
\hline 110 & $\begin{array}{l}\text { Phosphoenolpyruvate } \\
\text { Carboxykinase } 2 \text {, } \\
\text { mitochondrial }\end{array}$ & Pck2 & down & 0.35 & $<0.001$ & 70448.40 & 6.9 \\
\hline 140 & $\begin{array}{l}\text { Pyruvate Carboxylase, } \\
\text { mitochondrial }\end{array}$ & Pc & up & 5.10 & $<0.001$ & 129602.46 & 6.3 \\
\hline 139 & $\begin{array}{l}\text { Pyruvate Carboxylase, } \\
\text { mitochondrial }\end{array}$ & Pc & up & 3.78 & 0.001 & 129749.50 & 6.3 \\
\hline 20 & $\begin{array}{l}\text { Pyruvate Dehydrogenase E1 } \\
\text { (subunit alpha), } \\
\text { mitochondrial }\end{array}$ & Pdhal & up & 1.98 & $<0.001$ & 43203.63 & 8.5 \\
\hline 103 & $\begin{array}{l}\text { Pyruvate Dehydrogenase E1 } \\
\text { (subunit beta), mitochondrial }\end{array}$ & PDHB & up & 5.99 & $<0.001$ & 34813.76 & 5.6 \\
\hline 121 & Pyruvate Dehydrogenase E2 & Dlat & up & 2.22 & $<0.001$ & 67898.68 & 8.8 \\
\hline 9 & $\begin{array}{l}\text { Succinyl-CoA: } 3 \text {-ketoacid- } \\
\text { coenzyme A transferase } 1 \text {, } \\
\text { mitochondrial precursor }\end{array}$ & Oxct1 & up & 2.30 & $<0.001$ & 55953.00 & 8.7 \\
\hline 13 & $\begin{array}{l}\text { Succinyl-CoA: } 3 \text {-ketoacid- } \\
\text { coenzyme A transferase } 1 \text {, } \\
\text { mitochondrial precursor }\end{array}$ & Oxct1 & up & 2.22 & $<0.001$ & 55953.00 & 8.7 \\
\hline \multicolumn{8}{|c|}{ Inner Mitochondrial Membrane/Electron Transport Chain } \\
\hline 58 & $\begin{array}{l}\text { Electron Transfer } \\
\text { Flavoprotein (subunit beta) }\end{array}$ & Etfb & up & 2.16 & $<0.001$ & 27605.98 & 8.3 \\
\hline 32 & $\begin{array}{l}\text { Electron Transferring } \\
\text { Flavoprotein, alpha } \\
\text { polypeptide }\end{array}$ & Etfa & up & 2.12 & $<0.001$ & 35017.51 & 8.6 \\
\hline 105 & $\begin{array}{l}\text { Methylcrotonyl-coenzyme A } \\
\text { Carboxyl (alpha) }\end{array}$ & Mcca & down & 0.42 & $<0.001$ & 79265.35 & 7.7 \\
\hline 50 & $\begin{array}{l}\text { Succinate Dehydrogenase } \\
\text { Flavoprotein (subunit a), } \\
\text { mitochondrial precursor }\end{array}$ & Sdha & down & 0.53 & $<0.001$ & 72539.17 & 7.1 \\
\hline
\end{tabular}




\begin{tabular}{|c|c|c|c|c|c|}
\hline $\begin{array}{l}\text { ATP Synthase (subunit } \\
\text { alpha), mitochondrial }\end{array}$ & Atp5a1 & up & 2.81 & 0.002 & 59715.59 \\
\hline $\begin{array}{l}\text { ATP Synthase (subunit } \\
\text { alpha), mitochondrial }\end{array}$ & Atp5a1 & up & 1.48 & $<0.001$ & 59715.59 \\
\hline
\end{tabular}

\begin{tabular}{|c|c|c|c|c|c|c|c|}
\hline \multicolumn{8}{|c|}{ Nuclear Proteins } \\
\hline 30 & $\begin{array}{l}\text { Arginine/Serine-rich } \\
\text { Splicing Factor } 1\end{array}$ & Srsf1 & down & 0.35 & $<0.001$ & 24421.16 & 10.1 \\
\hline 59 & $\begin{array}{l}\text { Arginine/Serine-rich } \\
\text { Splicing Factor } 2\end{array}$ & Srsf2 & down & 0.38 & $<0.001$ & 25461.18 & 11.9 \\
\hline 101 & Nucleophosmin 1 & Npm1 & down & 0.25 & $<0.001$ & 32567.84 & 4.6 \\
\hline 54 & $\begin{array}{l}\text { Pre-mRNA Processing } \\
\text { Factor } 19 \text { (isoform 2) }\end{array}$ & Prpf19 & down & 0.60 & 0.009 & 55204.39 & 6.1 \\
\hline 105 & Prelamin A/C & Lmna & down & 0.42 & $<0.001$ & 65406.68 & 6.4 \\
\hline 56 & Prelamin A/C & Lmna & down & 0.52 & 0.008 & 65406.68 & 6.4 \\
\hline 66 & $\begin{array}{l}\text { Proliferation Associated } \\
\text { Protein } 2 \mathrm{G} 4\end{array}$ & $\mathrm{~Pa} 2 \mathrm{~g} 4$ & down & 0.38 & 0.002 & 43671.21 & 6.4 \\
\hline
\end{tabular}

\begin{tabular}{rlrrrrrr}
\multicolumn{7}{c}{ Transcription Factors } \\
\hline 3 & $\begin{array}{l}\text { Far-upstream Element } \\
\text { Binding Protein 1 }\end{array}$ & Fubp1 & down & 0.35 & 0.004 & 44933.88 & 9.0 \\
94 & $\begin{array}{l}\text { Far-upstream Element } \\
\text { Binding Protein 2 }\end{array}$ & Fubp2 & down & 0.64 & 0.001 & 79348.69 & 9.0 \\
75 & $\begin{array}{l}\text { KappaB Motif binding } \\
\text { phosphoprotein }\end{array}$ & Hivep3 & down & 0.27 & $<0.001$ & 51010.40 & 5.2 \\
76 & $\begin{array}{l}\text { KappaB Motif binding } \\
\text { phosphoprotein }\end{array}$ & Hivep3 & down & 0.35 & 0.002 & 51010.40 & 5.2 \\
TAR DNA-binding Protein & Tdp43 & down & 0.61 & $<0.001$ & 44519.29 & 6.3
\end{tabular}

mRNA Processing/Transport

\begin{tabular}{|c|c|c|c|c|c|c|c|}
\hline 83 & $\begin{array}{l}\text { Heterogenous Nuclear } \\
\text { Ribonucleoprotein A3 }\end{array}$ & Hnrnpa3 & down & 0.18 & 0.001 & 37063.20 & 8.5 \\
\hline 79 & $\begin{array}{l}\text { Heterogenous Nuclear } \\
\text { Ribonucleoprotein A3-like }\end{array}$ & Hnrnpa3 & down & 0.15 & $<0.001$ & 23529.62 & 7.1 \\
\hline 135 & $\begin{array}{l}\text { Heterogenous Nuclear } \\
\text { Ribonucleoprotein H }\end{array}$ & Hnrnph1 & down & 0.40 & $<0.001$ & 49168.40 & 5.9 \\
\hline 80 & $\begin{array}{l}\text { Heterogenous Nuclear } \\
\text { Ribonucleoproteins A2/B1 }\end{array}$ & Hnrnpa2b1 & down & 0.28 & 0.001 & 32440.44 & 8.7 \\
\hline 100 & $\begin{array}{l}\text { Heterogenous Nuclear } \\
\text { Ribonucleoproteins C1/C2 }\end{array}$ & Hnrpc & down & 0.12 & $<0.001$ & 34363.86 & 4.9 \\
\hline 99 & $\begin{array}{l}\text { Heterogenous Nuclear } \\
\text { Ribonucleoproteins } \mathrm{C} 1 / \mathrm{C} 2\end{array}$ & Hnrpc & down & 0.21 & $<0.001$ & 34363.86 & 4.9 \\
\hline 98 & $\begin{array}{l}\text { Heterogenous Nuclear } \\
\text { Ribonucleoproteins } \mathrm{C} 1 / \mathrm{C} 2\end{array}$ & Hnrpc & down & 0.40 & 0.002 & 34363.86 & 4.9 \\
\hline
\end{tabular}

Cell Signaling

\begin{tabular}{|c|c|c|c|c|c|c|c|}
\hline 118 & $\begin{array}{l}\text { TNF Receptor-Associated } \\
\text { Protein } 1\end{array}$ & Traf1 & up & 1.61 & 0.002 & 81155.13 & 6.4 \\
\hline \multicolumn{8}{|c|}{ GTP Synthesis } \\
\hline 34 & G-protein (beta subunit-like) & Gnb1 & up & 1.56 & $<0.001$ & 34996.55 & 8.1 \\
\hline \multicolumn{8}{|c|}{ Molecular Chaperones } \\
\hline 47 & $\begin{array}{l}\text { T-complex Protein } 1 \\
\text { (subunit beta) }\end{array}$ & Cct2 & down & 0.33 & $<0.001$ & 59614.11 & 8.0 \\
\hline 69 & Valosin-Containing Protein & Nvl & down & 0.41 & 0.002 & 89251.70 & 5.1 \\
\hline 70 & Valosin-Containing Protein & Nvl & down & 0.48 & $<0.001$ & 89251.70 & 5.1 \\
\hline
\end{tabular}


Homeostatic Maintenance

\begin{tabular}{|c|c|c|c|c|c|c|c|}
\hline 35 & Carbonic Anhydrase 2 & $\mathrm{Ca} 2$ & down & 0.10 & $<0.001$ & 29014.50 & 6.5 \\
\hline 90 & $\begin{array}{l}\text { Mercaptopyruvate } \\
\text { Sulfurtransferase }\end{array}$ & Mpst & up & 1.58 & $<0.001$ & 33018.53 & 6.1 \\
\hline 27 & Sialic Acid Synthase & Nans & down & 0.39 & 0.002 & 39998.36 & 6.6 \\
\hline \multicolumn{8}{|c|}{ Membrane Proteins } \\
\hline 49 & EH-domain Containing 4 & Ehd4 & down & 0.48 & 0.002 & 61453.32 & 6.1 \\
\hline 78 & $\begin{array}{l}\text { Voltage-Dependent Anion- } \\
\text { Selective Channel Protein } 2\end{array}$ & Vdac2 & up & 1.61 & $<0.001$ & 31712.58 & 7.4 \\
\hline \multicolumn{8}{|c|}{ Secreted Proteins } \\
\hline 102 & Alpha-s1 Casein & Csn1 & up & 4.05 & 0.001 & 34775.43 & 6.3 \\
\hline 1 & $\begin{array}{l}\text { Hemiferrin, Transferrin-like } \\
\text { Protein }\end{array}$ & LOC286987 & up & 1.64 & $<0.001$ & 24075.49 & 7.9 \\
\hline 130 & $\begin{array}{l}\text { Serotransferrin precursor } \\
\text { (bos taurus) }\end{array}$ & TF & up & 4.54 & $<0.001$ & 77615.72 & 7.1 \\
\hline 95 & Transferrin & Trf & down & 0.64 & $<0.001$ & 76627.67 & 6.9 \\
\hline 114 & Transferrin & $\operatorname{Trf}$ & up & 6.72 & $<0.001$ & 76627.67 & 6.9 \\
\hline 115 & Transferrin & $\operatorname{Trf}$ & up & 6.21 & $<0.001$ & 76627.67 & 6.9 \\
\hline 2 & Transferrin & $\operatorname{Trf}$ & up & 3.08 & $<0.001$ & 76627.67 & 6.9 \\
\hline 128 & Transferrin & Trf & up & 3.06 & 0.003 & 76627.67 & 6.9 \\
\hline 116 & Transferrin & Trf & up & 2.91 & $<0.001$ & 76627.67 & 6.9 \\
\hline \multicolumn{8}{|c|}{ Serum Protein } \\
\hline 120 & Albumin & Alb & up & 3.46 & 0.001 & 68647.71 & 5.8 \\
\hline 119 & Albumin & Alb & up & 2.82 & $<0.001$ & 68264.81 & 5.9 \\
\hline \multicolumn{8}{|c|}{ Unknown Function } \\
\hline 84 & $\begin{array}{l}\text { ES1 Protein homolog, } \\
\text { mitochondrial precursor }\end{array}$ & D10Jhu81e & up & 3.14 & 0.007 & 28072.78 & 9.0 \\
\hline
\end{tabular}

*values estimated by ExPASy - Bioinformatics Resource Portal (www.expasy.org) 


\subsection{Discussion}

In this chapter, we have presented a comparison of proteomic expression by the mammary epithelial cell during mid-pregnancy and peak lactation in the ICR mouse. The total gestation period for this breed of mouse is approximately 19 days. Day 10 of pregnancy was selected as the first day of cell isolation due not only to it being a halfway-point in gestation, but also due to previous studies showing day 10 as a point at which proliferation of the epithelium was still occurring yet alveoli had not yet begun to develop (Brisken, 2006). Day thirteen of lactation has been demonstrated to be the point of "peak lactation" in former mouse studies, so we selected day 10 post-parturition as our second isolation point, assuming the mammary gland would be fully differentiated to a lactating state and not yet transitioning into apoptosis or regression (Brisken, 2006).

Because our focus in this study is specific to the mammary epithelium, it was necessary to isolate only this cell type from the surrounding mammary gland. While plating and culturing the primary cells would have benefitted our sample volume and reduced contamination of dead cells and debris, our goal was to measure the proteins being expressed at these specific stages in vivo, and so we chose not to plate or culture the cells prior to protein extraction. The mammary epithelial layer, as it exists within the mammary gland, is spherical within alveoli and tight junctions are formed between cells. In order for individually isolated primary cells to attach to a flat, plastic surface such as a culture dish, it is very likely they must undergo significant proteomic changes to adapt to that new environment. Furthermore, if cells isolated from an animal during established 
lactation are encouraged to revert to a proliferative state in vitro, they cannot be assumed to express a proteome representative of a lactating mammary gland. A change in translation occurs over many hours and we cryogenically froze primary cells immediately after isolation. We decided that extracting protein samples from cells immediately postthaw would then be the best strategy for obtaining the most accurate representation of in vivo proteomic expression in the mammary epithelium.

As attempts to successfully validate the epithelial nature of our primary cells were unsuccessful, it is necessary to discuss the possible contaminating cell types in the sample population. The mammary epithelium exists within a fat pad in the mouse, which contains a great deal of adipose tissue and stroma. Adjacent to the epithelium are myoepithelial cells, the extracellular matrix, made up of fibroblasts, and blood vessels. Due to the extremely adherent properties of fibroblasts, they are likely removed from the epithelial population though a one-hour incubation period on a plastic surface during the cell isolation procedure. Adipose cells are removed through centrifugation, as this cell type is less massive than others and forms a layer above liquids used during the cell isolation procedure. Other stroma and blood should be absent from the sample due to collagenase and red blood cell lysis buffers also employed during the primary cell isolation process.

The majority of differences in global protein expression in mammary epithelial cells isolated from pregnant and lactating mice appear to be related to metabolism, structure and RNA processing. These proteins, and probably many that went undetected, must 
change in order to cease proliferation, re-structure and equip the cell with all necessary elements for the effective synthesis and secretion of milk components. While our lists of differently regulated proteins are broad and individual proteins may be associated with multiple roles or cell processes, this global expression data set will serve as a starting point for future validation experiments with more specific hypotheses.

\section{$\underline{\text { Metabolic Proteins }}$}

One group of metabolic proteins identified to change is related to the products of glycolysis, the pentose phosphate shunt and TCA cycle. The pentose phosphate shunt is a known driver of fatty acid production in the mammary epithelium, as NADPH is produced providing the reducing equivalent for fatty acid synthase function (Salway, 1994). Interestingly, we observed a down regulation of transketolase in the lactating mouse MEC, indicating a possible reduction in the use of the pentose phosphate pathway even though we saw an increase in the abundance of fatty acid synthase. In the rodent, NADPH can also be derived from the conversion of malate to pyruvate, termed the malate transhydrogenation cycle, and the cleavage of isocitrate into alpha-ketoglutarate within the cytosol. Additionally, we saw an upregulation on pyrroline-5-carboxylate reductase 2, the action of which has also been shown to be a source of NADPH production in the rat liver (Hagedorn, 1986). It is possible that the necessary increase in fatty acid synthesis is being driven by the product of those reactions, while glucose is being shunted towards lactose synthesis, glycolysis, and mitochondrial TCA cycle, rather than the pentose phosphate pathway. 
Again, we saw a number of pyruvate-associated proteins change. One of which, mercaptopyruvate sulfurtransferase, is an enzyme involved in cellular detoxification and is known to be inhibited by alpha-keto acids, pyruvate and alpha-ketoglutarate. In this experiment, we observed an up-regulation of the enzyme, which could possibly be the response of lactating epithelium to the buildup of pyruvate and alpha-ketoglutarate.

Within the mitochondrial protein changes, we observed an upregulation of aldehyde dehydrogenase and beta-hydroxy-butyrate dehydrogenase, which are associated with the breakdown of acetate and beta-hydroxy butyrate to provide additional sources of acetyl CoA, a substrate for the TCA cycle and subsequent ATP synthesis. Complementary to an increase in acetyl CoA were the increases observed in pyruvate dehydrogenase, which is the enzyme responsible for oxidation of pyruvate (the final product of glycolysis) into acetyl CoA, and pyruvate carboxylase, which catalyzes the carboxylation of pyruvate to oxaloacetate. Both oxaloacetate and acetyl CoA are necessary for the TCA cycle to progress, producing citrate from the condensation of the two substrates catalyzed by citrate synthase, an enzyme in which we also saw an upregulation. On a related note, the aldehyde dehydrogenase family of proteins have been noted as markers of stem cells within the human breast, and ALH2 specifically, one of the enzymes in which we detected an up-regulation upon differentiation, has also been noted to change upon differentiation in other cell types (Moreb, 2008). The aldehyde dehydrogenase family 4 member A1 protein is involved in the process of interconnecting the TCA cycle and urea cycle (The UniProt Consortium, 2012). Although there is no known urea cycle activity in the mammary epithelium, the up regulation of this enzyme is curious, as we saw another 
unexpected urea cycle-associated enzyme change in abundance in the MAC-T cell differentiation experiment. This occurrence would make an interesting point for further investigation.

The next reaction occurring in the TCA cycle is the reversible dehydration of citrate into isocitrate catalyzed by aconitase. We did observe an increase in the abundance of aconitase as well, which is interesting because both citrate and isocitrate may be shuttled from the mitochondria to participate in other metabolic pathways however, cytosolic citrate may be cleaved into oxaloacetate and acetyl CoA by the enzyme citrate lyase while isocitrate is restricted to the fate of becoming alpha-ketoglutarate through isocitrate dehydrogenase activity. Cytosolic isocytrate dehydrogenase abundance was down regulated in the cells isolated from lactating mice along with the mitochondrial enzymes alphaketoglutarate dehydrogenase, succinate dehydrogenase, serine hydroxy-methyl transferase and phosphenolpyruvate carboxykinase (PEPCK). These enzymes, excluding PEPCK, are associated with the TCA cycle and all catalyze steps following the production of alpha-ketoglutarate. The combination of all of these changes indicate a build up of citrate and isocitrate within the mitochondria, and due to the reversibility of aconitase activity, both products may be shuttled out of the mitchondria, dependent on metabolic demands. In this way, citrate is likely contributing to fatty acid synthesis in a way that is not possible in the ruminant mammary epithelial cell. Not only does citrate produce acetyl CoA as a precursor for fatty acid synthesis, but the conversion of oxaloacetate to malate and then oxidation of malate to pyruvate, is another source of NAPDH. Pyruvate produced in this fashion may then return to the mitchondria to 
continue the cycle. The observed down regulation of the enzyme alpha enolase, which catalyzes the final step of glycolysis could be due to the cyclical recycling of pyruvate through the steps described. If glucose is not being used for production of pyruvate, it may be spared for the synthesis of lactose or converted to glycerol for milk fat.

\section{$\underline{\text { Heat Shock Proteins }}$}

Several heat shock proteins (HSP) were identified as changing in abundance between states of pregnancy and lactation in the isolated mammary epithelial cell populations. HSPs are molecular chaperones that facilitate the correct folding of proteins and are associated with function and formation of the cytoskeleton. It is not surprising that the differentiation of the mammary epithelium, in vivo, would require structural reorganization, which may be facilitated by this family of proteins.

\section{Cytoskeletal Proteins}

Structurally, we saw a down-regulation in keratins 8 and 18, which are associated with epithelial differentiation and filament reorganization, respectively. As differentiated cells were isolated from mice at peak lactation, it is expected that cells would be fully differentiated and not undergoing major structural changes they would during pregnancy and proliferation. Coincidentally, keratin 18, or CK18, was the marker of epithelial origin selected for use in flow cytometry (see appendix). It is interesting that we saw a downregulation of this protein, as previous studies suggested use of this antibody due to uniform expression in luminal epithelial cells (O’Hare, 1991). Keratin 5 however, was up-regulated, which is interesting as this is also a filament associated with the process of 
differentiation which these cells should no longer be undergoing. This change in specific intermediate filaments is a point of differentiation that deserves deeper research.

\section{$\underline{\text { Nuclear Proteins }}$}

Within the group of resident nuclear proteins that were identified to change, there were seven examples of heterogeneous nuclear ribonucleoproteins (hnRNP) and all decreased in abundance after differentiation. These particles are generally bound to pre-mRNA to signal that the mRNA is not yet ready to be translocated to the cytoplasm. Once the correct splicing has occurred, mature mRNA may leave the nucleus, and hnRNPs remain bound to spliced-out introns, then signaling for degredation (Papadopoulou, 2012). The down-regulation of every hnRNP we detected to change signifies either a reduction in the mRNA for genes with which these specific hnRNPs are associated, or a change in the way the differentiated cell directs splicing and mRNA processing.

Pre-mRNA processing factor 19 , isoform 2 , which was down regulated in the lactating mouse mammary epithelium, was also down regulated in differentiated MAC-T cells, indicating that this protein may play a universal role in the mammary epithelial cell specifically during proliferation. In the mouse brain, expression of the beta isoform of the pre-mRNA processing factor 19 gene (Prf19b) caused differentiation of neuronal cells, but inhibited differentiation of astroglial cells indicating that alternative splicing of this gene plays a very specific role in cell fate decision (Urano, 2006). Perhaps, this isoform of the Prf19 gene is also required for the differentiation of mammary epithelial cells. 


\section{CHAPTER 4 - Summary}

These experiments present the same cell type from two different species utilizing very different metabolic processes that overall, result in a very similar outcome: lactogenesis. In other words, there are multiple routes to the same endpoint, and the pathways taken to differentiation could possibly be determined by the diet, absorption and subsequent nutrients available to the mammary gland.

The first experiment presented within this document compared the protein expression profiles of MAC-T cells from before and after induced in vitro differentiation. The data produced through this experiment supported earlier research from our lab which not only revealed a direct effect of growth hormone on MAC-T, but suggested the effect may be similar to the changes occurring naturally during differentiation of the cell. By observing the changes to the proteome that occurred between proliferation and differentiation of MAC-T cells, we not only confirmed that there are several similarities between differentiation and $\mathrm{GH}$ treatment, but also uncovered a host of proteins that we did not expect to change. The new list of identified proteins provides a great deal of novel information about the mammary epithelium and the molecular processes that are possibly involved in lactogenesis.

The second study was designed in attempt to provide an in vivo comparison to this experiment, while simultaneously offering insight into the inherent differences between mammary glands from ruminant and rodent animals. As the diets and overall metabolic 
systems in these two species are drastically different, it is interesting to see evidence that those differences are mirrored on the molecular level in the way mammary epithelial cells use or spare certain nutrients, depending on availability, to efficiently synthesize all of the essential components of milk.

While the differing proteins between primary MEC isolated before and after the initiation of lactation provide an interesting basis for further study, it is important to remember that the two stages at which we isolated our protein samples do not provide a progressive picture of the changes occurring within the mammary epithelium. These data afford a great number of possibilities for studies to be developed providing a clearer picture of individual pathways and metabolic changes by observing additional time-points or by employing more specific, quantitative technologies. Western blotting is an excellent tool for measuring specific proteins of interest and would negate the challenge of missing low-abundance proteins or misguided analysis due to post-translational modifications, which are possible with our methods of $2 \mathrm{D}$ electrophoresis. However, there are added challenges to the Western blot such as antibody specificity, difficulty identifying important post-translational modifications and statistical analyses that would require careful consideration. Additionally, adding other developmental stages, such as pre versus post puberty and pre versus post established pregnancy would be interesting to study in comparison to our findings.

Some of the data collected in these experiments has paralleled previous research in mammary gland biology, some appears to challenge the current dogma and some has 
incited our curiosity in pathways never before explored in the mammary epithelium. While much necessary investigation still remains to make clear the roles of certain proteins and pathways in the evolution to a lactogenic phenotype, the analysis of these extensive protein lists may provide a platform from which further research may be based. 


\section{LIST OF REFERENCES}

Akers, et al., 2005 Ovarian and IGF-I axis control of mammary development in prepubertal heifers. Domestic Animal Endocrinology 29(2): 259-267.

Ali, et al., 2001 Cellular transformation by SV40 large T antigen: interaction with host proteins. Seminars in Cancer Biology 11(1): 15-23.

Amos, et al., 1985 Influence of milking frequency on productive and reproductive efficiencies of dairy cows. Journal of Dairy Science 68(3): 732-739.

Anderson, et al., 2007 Secretory activation in the mammary gland: it's not just about milk protein synthesis! Breast Cancer Research 9(1): 204.

Asselin-Labat, et al., 2010 Control of mammary stem cell function by steroid hormone signaling. Nature 465(7299): 798-802.

Ball, et al., 1988 Prolactin regulation of beta-casein gene-expression and of a cytosolic $120-\mathrm{kD}$ protein in a cloned mouse mammary epithelial-cell line. Embo Journal 7(7): 2089-2095.

Bauman, et al., 2000 Regulation of Nutrient Partitioning During Lactation: Homeostasis and Homeorhesis Revisited. Ruminant physiology: Digestion, Metabolism, Growth and Reproduction 311-328.

Bauman, et al., 2011 Mammary Gland, Milk Synthesis and Secretion Encyclopedia of Dairy Sciences. Academic Press 2340-2346.

Bell and Bauman, 2000 Regulation of Macronutrient Partitioning between Maternal and Conceptus Tissues in the Pregnant Ruminant. Ruminant Physiology: Digestion, Metabolism, Growth and Reproduction 275-294.

Bequette, et al., 1997 Amino acid supply and metabolism by the ruminant mammary gland. The Proceedings of the Nutrition Society 56(2): 593-605.

Berry, et al., 2001 A local increase in the mammary IGF-1: IGFBP-3 ratio mediates the mammogenic effects of estrogen and growth hormone. Domestic Animal Endocrinology 21(1): 39-53.

Berry, et al., 2003Interactions between the ovary and the local IGF-I axis modulate mammary development in prepubertal heifers. The Journal of Endocrinology 177(2): 295-304.

Brackley, et al., 2011 Interactions between the actin filament capping and severing protein gelsolin and the molecular chaperone CCT: evidence for nonclassical substrate interactions. Cell Stress \& Chaperones 16(2): 173-179. 
Brisken, et al., 2006 Alveolar and lactogenic differentiation. Journal of Mammary Gland Biology and Neoplasia 11(3-4): 239-248.

$\mathrm{Bu}$, et al., 2011 Keratin 6a marks mammary bipotential progenitor cells that can give rise to a unique tumor model resembling human normal-like breast cancer. Oncogene 30(43): 4399-4409.

Capuco, et al., 2002 Postnatal mammary ductal growth: three-dimensional imaging of cell proliferation, effects of estrogen treatment, and expression of steroid receptors in prepubertal calves. Tissue \& Cell 34(3): 143-154.

Chew, et al., 2000 The LIM and SH3 domain-containing protein, lasp-1, may link the cAMP signaling pathway with dynamic membrane restructuring activities in ion transporting epithelia. Journal of Cell Science 113(11): 2035-2045.

Coll, et al., 1995 Targeted distribution of viniculin genes in F9 and embryonic stem-cells changes cell morphology, adhesion and locomotion. Proceedings of the National Academy of Sciences of the United States of America 92(20): 9161-9165.

Creutz, et al., 1992 The annexins and exocytosis. Science 258(5084): 924-931.

Danielson, et al., 1984 Epithelial mouse mammary cell line exhibiting normal morphogenesis in vivo and functional differentiation in vitro. Proceedings of the National Academy of Sciences of the United States of America 81(12): 37563760 .

Delamaire, et al., 2006 Longer milking intervals alter mammary epithelial permeability and the udder's ability to extract nutrients. Journal of Dairy Science. 89(6): 20072016.

Desrivieres, et al., 2003 Comparative proteomic analysis of proliferating and functionally differentiated mammary epithelial cells. Molecular \& Cellular Proteomics 2(10): 1039-1054.

Elis, et al., 2011 Unbound (bioavailable) IGF1 enhances somatic growth. Disease Models \& Mechanisms 4(5): 649-658.

Etherton, et al., 1998 Biology of somatotropin in growth and lactation of domestic animals. Physiol Rev 78(3): 745-761.

Foster, et al., 1977 Changes in mouse mammary epithelial-cell size during mammarygland development. Cell Differentiation 6(1): 1-8.

Gadkar-Sable, et al., 2005 Progesterone receptors: various forms and functions in reproductive tissues. Front Bioscience 10: 2118-2130.

Gallego, et al., 2001 Prolactin, growth hormone, and epidermal growth factor activate stat5 in different compartments of mammary tissue and exert different and 
overlapping developmental effects. Developmental Biology 229(1): 163-175.

Gjoevski, et al., 2011 Integrated morphodynamic signalling of the mammary gland. Nature Reviews Molecular Cell Biology 12(9): 581-593.

Gnoni, et al., 2009 Quercetin inhibits fatty acid and triacylglycerol synthesis in rat-liver cells. European Journal of Clinical Investigation 39(9): 761-768.

Guinard-Flament, et al., 2006 Changes in mammary uptake and metabolic fate of glucose with once-daily milking and feed restriction in dairy cows. Reproduction, Nutrition, and Development 46(5): 589-598.

Hagedorn, et al., 1986 Demonstration of a NADPH-linked delta 1-pyrroline-5carboxylate-proline shuttle in a cell-free rat liver system. Biochimica et Biophysica Acta 884(1): 11-17.

Haines, et al., 2011 Argininosuccinate synthase: at the center of arginine metabolism. International Journal of Biochemistry and Molecular Biology 2(1): 8-23.

Haug, et al., 2007 Bovine milk in human nutrition--a review. Lipids in Health and Disease (6): 25.

Hens, et al., 2005 Key stages of mammary gland development: molecular mechanisms involved in the formation of the embryonic mammary gland. Breast Cancer Research 7(5): 220-224.

Hovey, et al., 1998 The proliferation of mouse mammary epithelial cells in response to specific mitogens is modulated by the mammary fat pad in vitro. In Vitro Cellular \& Developmental Biology. Animal 34(5): 385-392.

Hovey, et al., 1999 Regulation of mammary gland growth and morphogenesis by the mammary fat pad: A species comparison. Journal of Mammary Gland Biology and Neoplasia 4(1): 53-68.

Huynh, et al., 1991 Establishment of bovine mammary epithelial cells (MAC-T): an in vitro model for bovine lactation. Experimental Cell Research 197(2): 191-199.

Jenness, et al., 1979 The composition of human milk. Seminars in Perinatology 3(3): 225-239.

Johnson, et al., 2010 Growth hormone alters lipid composition and increases the abundance of casein and lactalbumin mRNA in the MAC-T cell line. Journal of Dairy Research 77: 199-204.

Kaulsay et al., 2001 The effects of autocrine human growth hormone (hGH) on human mammary carcinoma cell behavior are mediated via the hGH receptor. Endocrinology 142(2): 767-777. 
Keys, et al., 1997 Bovine mammary explant versus primary cell cultures: effect of bovine somatotropin and insulin-like growth factor-I on DNA content and protein synthesis. In Vitro Cellular \& Developmental Biology. Animal 33(3): 206-211.

Knight, et al., 1982 Mammary cell proliferation in mice during pregnancy and lactation in relation to milk yield. Quarterly Journal of Experimental Physiology 67(1): 165177.

Knight, et al., 2001 Overview of prolactin's role in farm animal lactation. Livestock Production Science 70(1-2): 87-93.

Kuhla, et al., 2011 Involvement of Skeletal Muscle Protein, Glycogen, and Fat Metabolism in the Adaptation on Early Lactation of Dairy Cows. Journal of Proteome Research 10(9): 4252-4262.

Laliotis, et al., 2010 Comparative Approach of the de novo Fatty Acid Synthesis (Lipogenesis) between Ruminant and Non Ruminant Mammalian Species: From Biochemical Level to the Main Regulatory Lipogenic Genes. Current Genomics 11(3): 168-183.

Larson, et al., 1979 Biosynthesis and secretion of milk proteins: a review. The Journal of Dairy Research 46(2): 161-74.

Lecchi, et al., 2012 Widespread expression of SAA and Hp RNA in bovine tissues after evaluation of suitable reference genes. Veterinary Immunology and Immunopathology 145(1-2): 556-562.

Levine, et al., 2010 The control of the metabolic switch in cancers by oncogenes and tumor suppressor genes. Science 330(6009): 1340-1344.

Lollivier, et al., 2006 Oxytocin stimulates secretory processes in lactating rabbit mammary epithelial cells. The Journal of Physiology 570(1): 125-140.

MacMahon, et al., 1970 Age at first birth and breast cancer risk. Bulletin of the World Health Organization 43(2): 209-221.

Matitashvili, et al., 1997 An in vitro approach to ruminant mammary gland biology. Biotechnology Advances 15(1): 17-41.

Mayanagi, et al., 2011 Diversification of caldesmon-linked actin cytoskeleton in cell motility. Cell Adhesion \& Migration 5(2): 150-159.

Mellenberger, et al., 2009 Metabolic adaptations during lactogenesis: fatty acid and lactose synthesis in cow mammary tissue. Journal of Mammary Gland Biology and Neoplasia 14(3): 261-268.

Miriam-Webster, 2012 "mammal" definition. Online Dictionary http://www.merriamwebster.com/dictionary/mammal 
Moffat, et al., 1999 Structure and expression of the mouse growth hormone receptor/growth hormone binding protein gene. Journal of Molecular Endocrinology 23(1): 33-44.

Mol, et al., 1995 Growth hormone messenger mRNA in mammary gland tumors of dogs and cats. Journal of Clinical Investigation 95(5): 2028-2034.

Moreb, et al., 2008 Aldehyde dehydrogenase as a marker for stem cells. Current Stem Cell Research Theory 3(4): 237-246.

Moriera, et al., 2010 Lapatinib and breast cancer: current indications and outlook for the future. Expert Review of Anticancer Therapy 10(8): 1171-1182.

Morishita, et al., 1996 Effect of dietary corn oil, butter and beef tallow on the cecal microflora and short-chain fatty acids in rats. Bioscience and Microflora 15(1): 27-30.

Mukhina, et al., 2006 Autocrine growth hormone prevents lactogenic differentiation of mouse mammary epithelial cells. Journal of Endocrinology 147(4): 1819-1829.

$\mathrm{Ng}$, et al., 1997 Growth hormone treatment induces mammary gland hyperplasia in aging primates. Nature Medicine 3(10): 1141-1144.

NIH (National Institute of Health), 2011 Biomarkers NIEHS - NIH website http://www.niehs.nih.gov/health/topics/science/biomarkers/index.cfm

O'Hare, et al., 1991 Characterization in vitro of luminal and myoepithelial cells isolated from the human mammary gland by cell sorting. Differentiation; Research in Biological Diversity 46(3): 209-221.

O'Quinn, et al., 2002 Arginine catabolism in lactating porcine mammary tissue. Journal of Animal Science 80(20): 467-474.

Ou, et al., 2008 Novel breast cancer biomarkers identified by integrative proteomic and gene expression mapping. Journal of Proteome Research 7(4): 1518-1528.

Papadopoulou, et al., 2012 Expression profile and interactions of hnRNP A3 within hnRNP/mRNP complexes in mammals. Archives of biochemistry and biophysics 523(2): 151-160.

Perry, et al., 2008 The contribution of growth hormone to mammary neoplasia. Journal of Mammary Gland Biology and Neoplasia 13(1): 131-145.

Picciano, et al., 2003 Pregnancy and lactation: physiological adjustments, nutritional requirements and the role of dietary supplements. The Journal of Nutrition 133(6): 1997-2002.

Puckelwartz, et al., 2011 Gene expression, chromosome position and lamin A/C 
mutations. Nucleus 2(3): 162-167.

Raccurt, et al., 2002 High stromal and epithelial human GH gene expression is associated with proliferative disorders of the mammary gland. Journal of Endocrinology 175(2): 307-318.

Rhoads, et al., 2007 Translational regulation of milk protein synthesis at secretory activationJournal of Mammary Gland Biology and Neoplasia 12(4): 283-292.

Rius, et al., 2010 Regulation of protein synthesis in mammary glands of lactating dairy cows by starch and amino acids. Journal of Dairy Science 93(7): 3114-3127.

Rowling, et al., 1994 A single purification procedure for resident proteins of the ER lumen. Protein Expression and Purification 5(4): 331-336.

Rudolph, et al., 2011 Prolactin-mediated regulation of lipid biosynthesis genes in vivo in the lactating mammary epithelial cell. Endocrinology and Metabolism 300(6): 1059-1068.

Russo, et al., 2005 The protective role of pregnancy in breast cancer. Breast Cancer Research 7(3): 131-142.

Salway, JG, 1994 Metabolism at a Glance. Blackwell Publishing, Ltd.

Saotome, et al., 2004 Ezrin is essential for epithelial organization and villus morphogenesis in the developing intestine. Developmental Cell 6(6): 855-864.

Shackleton, et al., 2006 Generation of a functional mammary gland from a single stem cell. Nature 439(7072): 84-88.

Shaper, et al., 1998 Beta1,4-galactosyltransferase and lactose biosynthesis: recruitment of a housekeeping gene from the nonmammalian vertebrate gene pool for a mammary gland specific function. Journal of Mammary Gland Biology and Neoplasia 3(3): 315-324.

Shoyab, et al., 1989 Structure and function of human amphiregulin: a member of the epidermal growth factor family. Science 243(4894): 1074-1076.

Shyamala, et al., 2002 Cellular expression of estrogen and progesterone receptors in mammary glands: regulation by hormones, development and aging. The Journal of Steroid Biochemistry and Molecular Biology 80(2): 137-148.

Siewit, et al., 2009 Cadmium Promotes Breast Cancer Cell Proliferation by Potentiating the Interaction between ER alpha and c-Jun. Molecular Endocrinology 24(5): 981-992.

Smalley, MJ, 2010 Isolation, culture and analysis of mouse mammary epithelial cells. Methods Molecular Biology 633: 139-70. 
Stingl, et al., 2011 Estrogen and progesterone in normal mammary gland development and in cancer. Hormones \& Cancer 2(2): 85-90.

Sunehag , et al., 2003 Contribution of plasma galactose and glucose to milk lactose synthesis during galactose ingestion. The Journal of Clinical Endocrinology and Metabolism 88(1): 225-229.

Telang, et al., 1989 In vitro biotransformation of estradiol by explant cultures of murine mammary tissues. Breast Cancer Research and Treatment 13(2): 173-181.

The UniProt Consortium, 2012 Reorganizing the protein space at the Universal Protein Resource (UniProt). Nucleic Acids Research 40: D71-D75.

Trott, et al., 2009 Tissue-specific regulation of porcine prolactin receptor expression by estrogen, progesterone, and prolactin. Journal of Endocrinology 202(1): 153-166.

Tucker, et al., 1981 Physiological control of mammary growth, lactogenesis, and lactation. Journal of Dairy Science 64(6): 1403-1421.

Urano, et al., 2006 Involvement of the mouse Prp19 gene in neuronal/astroglial cell fate decisions. The Journal of Biological Chemistry 281(11): 7498-7514.

Van Soest, 1994 Nutritional Ecology of the Ruminant. Cornell University Press.

Visvader, et al., 2009 Keeping abreast of the mammary epithelial hierarchy and breast tumorigenesis. Genes \& Development 23(22): 2563-2577.

Xu, et al., 2011 Growth hormone signaling in human T47D breast cancer cells: potential role for a growth hormone receptor-prolactin receptor complex. Molecular Endocrinology 25(4): 597-610.

Yogi, et al., 2012 Mammary gland morphological and gene expression changes underlying pregnancy protection of breast cancer tumorigenesis. Physiological Genomics 44(1): 76-88.

Zavizion, et al., 1995 Subcloning the MAC-T bovine mammary epithelial cell line: morphology, growth properties, and cytogenic analysis of clonal cells. Journal of Dairy Science 78(3): 515-527.

Zhao, et al., 1996 Localization and gene expression of glucose transporters in bovine mammary gland. Comparative Biochemistry and Physiology Part B: Biochemistry and Molecular Biology 15(1): 127-134.

Zhou, et al., 2008 Growth hormone can induce expression of four major milk protein genes in transfected MAC-T cells. Journal of Dairy Science 91(1): 100-108.

Zhu, et al., 2011 Prognostic Evaluation of CapG, Gelsolin, P-gp, GSTP1, and Topo-II Proteins in Non-Small Cell Lung Cancer. Anatomical Record-Advances in 
Integrative Anatomy and Evolutionary Biology 295(2): 208-214. 


\section{APPENDIX}

\section{Flow Cytometry}

Although we attempted to verify the epithelial origin of primary cells isolated from pregnant and lactating mice through application of flow cytometry, our efforts were relatively unsuccessful. Cytokeratin 18 (CK18) was selected as a positive marker as it is a cytoskeletal filament associated specifically with luminal-epithelial cells and not squamous, myoepithelial cells or fibroblasts which are possible contaminating cell types in a primary mammary epithelial cell isolation such as this one (O'Hare, 1991). Additionally, CK18 and had previously been demonstrated to be uniformly expressed by MAC-T populations (Zavizion, 1995).

A FITC-conjugated primary anti-mouse CK18 antibody was purchased from Abcam (Cambridge, MA).

Primary cells isolated for proteomic analysis from pregnant and lactating mice were thawed from storage in liquid nitrogen. Additionally, HC11 cells (an immortal mouse mammary epithelial cell line) were thawed and used as a positive control. 3T3 cells were selected as a negative control as this fibroblast cell line is murine in origin, but should not express CK18. Remaining cells were fixed and permeabilized through incubation in $100 \%$ methanol at $-20^{\circ} \mathrm{C}$ for 30 minutes. Cells were then centrifuged and rinsed in PBS. CK18 antibody was diluted from $100 \mathrm{ug} / \mathrm{ml}$ to $10 \mathrm{ug} / \mathrm{ml}$ in $3 \%$ Bovine Serum Albumin (BSA) and then to a final concentration of $1 \mathrm{ug} / \mathrm{ml}$ in cell suspension. All cells were incubated in the dark at $4^{\circ} \mathrm{C}$ for 30 minutes. Control cells of each variety were incubated 
simultaneously under the same conditions with an equal volume of 3\% BSA containing no antibody. After incubation, cells were washed $3 \mathrm{x}$ through centrifugation at $400 \mathrm{x} \mathrm{g}$ for 5 minutes in PBS. Each pellet was diluted to a final concentration of $<500$ cells/ul before analysis by flow cytometry. Levels of florescence emitted by each cell corresponded with the expression of CK18. Fluorescence data between cell types was overlaid and compared with viability counts to estimate the percentage of epithelial cells isolated. 


\section{$\underline{\text { Results }}$}

A.

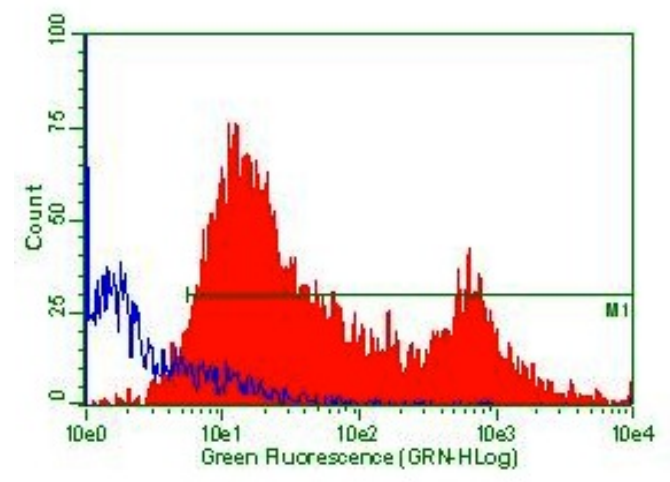

B.

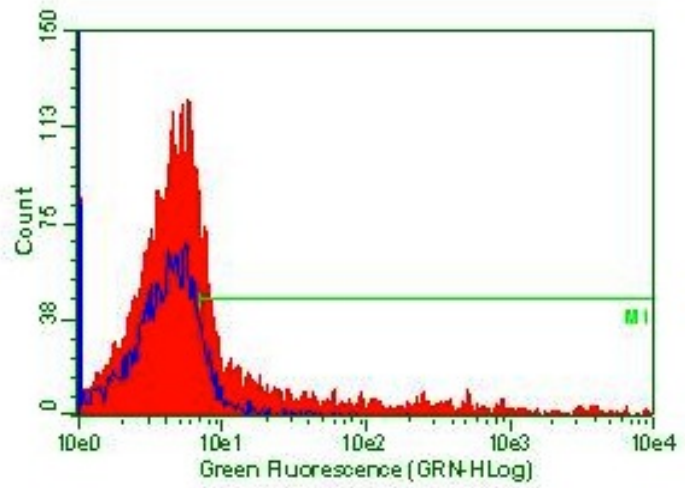

Figure __. Cells isolated from pregnant mice that were (A) plated overnight were $87 \%$ viable and stained positively with CK18 FITC conjugated antibody (solid peaks) as compared to the negative control (3T3 fibroblasts), overlaid in the image. (B) Cells tested directly after thawed from liquid $\mathrm{N}$ were only $40 \%$ viable and consequently, less fluorescence was measured as compared to the negative control.

A.

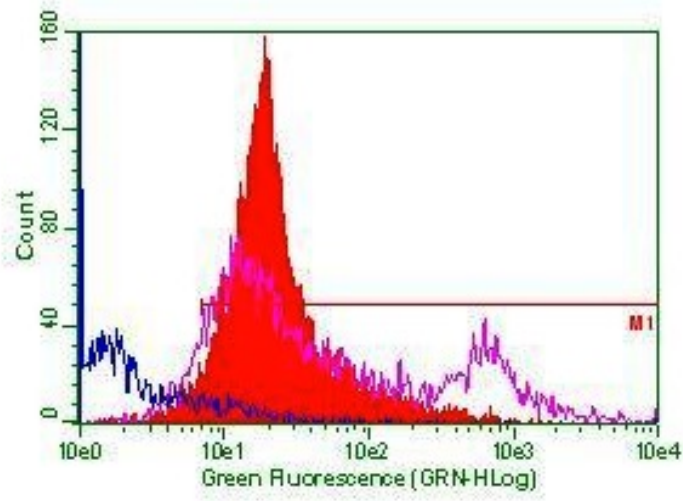

B.

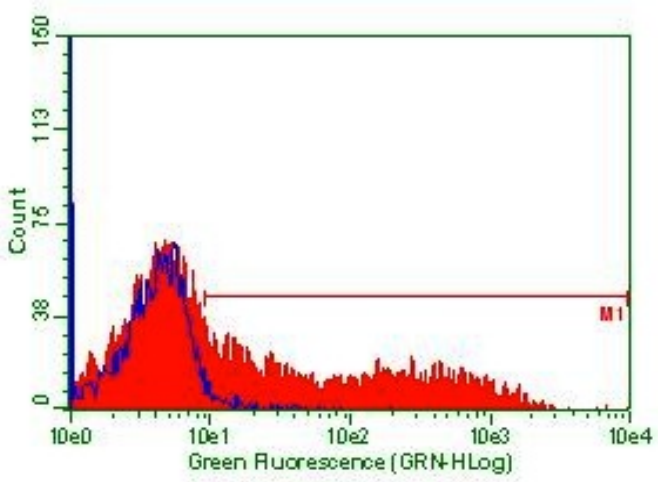

Figure _. Cells isolated from lactating mice that were (A) plated overnight were $78 \%$ viable and stained positively with CK18 FITC conjugated antibody (solid peaks) as compared to the negative control (3T3 fibroblasts), as shown by the dark line overlaid in 
the image. The lighter overlay represents two peaks of fluorescence of the cells from pregnant mice after the same culture period. (B) Cells tested directly after thawed from liquid $\mathrm{N}$ were only $41 \%$ viable and consequently, less fluorescence was measured as compared to the negative control. 